\title{
Scanning Electron Microscopy
}

Volume 3

Number 1 3rd Pfefferkorn Conference

Article 27

1984

\section{Low Voltage Scanning Electron Microscopy}

James B. Pawley

University of Wisconsin

Follow this and additional works at: https://digitalcommons.usu.edu/electron

Part of the Biology Commons

\section{Recommended Citation}

Pawley, James B. (1984) "Low Voltage Scanning Electron Microscopy," Scanning Electron Microscopy.

Vol. 3 : No. 1 , Article 27.

Available at: https://digitalcommons.usu.edu/electron/vol3/iss1/27

This Article is brought to you for free and open access by the Western Dairy Center at DigitalCommons@USU. It has been accepted for inclusion in Scanning Electron Microscopy by an authorized administrator of DigitalCommons@USU. For more information, please contact digitalcommons@usu.edu.

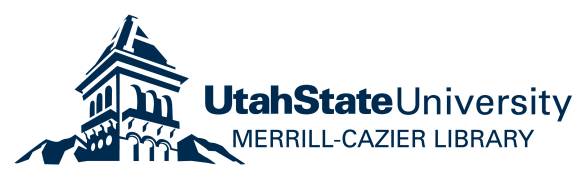


LOW VOLTAGE SCANNING ELECTRON MICROSCOPY

James B. Pawley

Zoology Department and

High Voltage Electron Lab

University of Wisconsin

1675 Observatory Drive

Madison, WI 53706

Phone No.: (608) 263-3147

\section{Abstract}

The scanning electron microscope (SEM) usually operates with a beam voltage, $V_{0}$, in the range of 10-30 kV, even though many early workers suggested the use of lower voltages to increase topographic contrast and to reduce specimen charging and beam damage. The chief reason for this contradiction is low instrumental performance when $V_{0}=1-3 \mathrm{kV}$. The problems include low source brightness, greater defocussing due to chromatic aberration, greater sensitivity to internal and external stray fields and difficulty in collecting the secondary electron signal without defocussing the probe. Recently considerable efforts have been made to overcome these problems because the semiconductor industry, which is now the major user of the SEM, has found that low $V_{0}$ is necessary to reduce beam damage. The resulting equipment has greatly improved performance at low $\mathrm{kV}$ and substantially removes the practical deterrents to operation in this mode on other types of samples. This paper reviews the advantages of low voltage operation for topographic imaging, recent progress in instrumentation and describes a prototype instrument designed and built for optimum performance at $1 \mathrm{kV}$. Other 1 imitations to high resolution topographic imaging such as surface contamination, the de-localized nature of the inelastic scattering event and radiation damage are also discussed.

Key words: Low Voltage Scanning Electron Microscopy, Secondary electron contrast, High resolution, Topographic imaging

\section{Introduction}

As the beam voltage, $V_{0}$ is reduced in the range $30-1 \mathrm{kV}$, three physical parameters relevant to specimen damage, surface charging, and topographic contrast also change. The secondary electron coefficient, $\delta$, increases to $>1$ while the electron range $(R)$ and the energy deposited per electron $\left(e V_{0}\right)$ both decrease. When $\delta$ is large there is less surface charging on insulating samples and there is more signal per beam electron, while a smaller $R$ means the beam/specimen interaction is more localized and topographic contrast is higher. This was recognized early by Thornley (1960), but widespread use of the SEM in the 1-3 $\mathrm{kV}$ range was delayed by technical limitations that can be grouped in four categories: 1) low source brightness; 2) increased effect of chromatic aberration; 3) increased sensitivity to stray fields; 4) defocusing of the probe by the secondary electron collection field. With a few exceptlons (Welter and Coates, 1974) these disincentives prevented significant efforts to improve low voltage SEM (LVSEM) performance. More recently, however, SEM studies of semiconductors were found to be limited by the damage caused by the beam and the most effective way to $1 \mathrm{imit}$ this damage was to use $V_{0}$ in the range $0.5-1.5 \mathrm{kV}$ (Keery et a 1. 1976, Miyoshi et al. 1982). The fact that the semiconductor industry, which presently represents over $80 \%$ of the SEM market, urgently needed to monitor production procedures and final performance without damaging the specimen provided a new impetus for the development of equipment optimized for low voltage operation. (Tamura et al. 1980; Todokoro et a1. 1980, 1983, 1984; Buchanan, 1982, 1983; Buchanan and Menzel, 1984; Pomposo and Coates, 1983; Pawley and Wa 11, 1982; Boyes 1984; Pawley, $1984 \mathrm{a}, \mathrm{b}$, other papers in this volume).

It is the purpose of this paper to draw attention to these developments in the belief that the low voltage capability of this new equipment will find widespread application outside the field of semiconductor research. The advantages of lowvoltage operation will be discussed particularly in regard to the possibility that it may eventually provide the ultimate in high resolution topographic images of biological samples (Pawley, 1984a,b). This will be followed by a description of both the instrumentation problems associated 
with operating the SEM at high resolution with $V_{0}$ $\simeq 1 \mathrm{kV}$ and the strategies that have been developed or proposed to overcome these problems. A prototype instrument designed to produce a 1-2 nm beam at $1 \mathrm{kV}$ will be described along with a discussion of preliminary results and problems encountered. Finally there is a brief discussion of the limitations posed to the ultimate topographic resolution of an ideal instrument by radiation damage, sample-derived surface contamination and the delocalized nature of the in elastic scattering event.

\section{The Advantages of LVSEM}

Most of the advantages of using an SEM with Vo $\approx 1 \mathrm{kV}$ derive directly from the fact that electrons impinging on the surface of a solid with less energy, penetrate into it a shorter distance and also have a higher cross-section for producing secondaries near the surface where they have a higher chance of escaping (Kotera et al. 1981). As a result, $\delta$ approaches unity, charging artifacts on insulating surface become less pronounced and the signal/beam-electron is increased. Also less energy $\left(e V_{o}\right)$ is deposited in the sample and on insulating samples, charge is not injected and trapped so far beneath the surface.

All of these features are important for the study of uncoated resist patterns or passivation layers on semiconductor devices or for viewing voltage contrast effects. Relative freedom from charging artifacts is an obvious advantage, but it is even more important to avoid high surface potentials that might cause breakdown in the device and to reduce beam penetration because charges trapped in insulating regions can distort the energy band structure of the device, degrading and possibly destroying it. At $1 \mathrm{kV}$, charge injection is restricted to the outer $0.02 \mu \mathrm{m}$ or so, rather than 130 times that depth at $30 \mathrm{kV}--\mathrm{a}$ crucial difference in devices only a few micrometers deep. Finally, both the silicon and the resist layer on $i$ ts surface are composed of materials having relatively low atomic number $(Z)$. At high beam voltages, very little surface detall can be seen on uncoated low Z samples, but at $1 \mathrm{kV}$ the energy is deposited nearer to the beam entry point and so contrast produced by topographical variations is proportionately larger. Aspects of the study of semiconductors in the SEM that emphasize the utility of low voltage operation are discussed by Pfeiffer (1982), Todokoro et al. $(1983,1984)$, Tamura et al. (1980), Buchanan and Menzel, 1984 and Brandis et al (1984) and low voltage electron lithography is described by Yau et al. (1981), Varnell (1981) and Polasko et al. (1983) Newman et al (1984) by contributions from Pfelffer, Russell, orloff and Murray in this volume. Al though the subjects covered by these authors are in large part responsible for recent instrumental improvements in the LVSEM, they will not be discussed specifically further here. Contrast and charging will now be considered in more detail.

\section{Topographic Imaging in the SEM}

At low magnification, the secondary electron image from the SEM is easily interpreted by the brain to yield a fairly accurate understanding of the shape of the surface of the specimen. It does so because there is a rough equivalence between the secant laws relating the apparent brightness of a diffusely-illuminated matte surface and $i$ ts angle with the line of sight on the one hand and the variation of $\delta$ with incidence angle on the other (Everhart et a 1., 1959). Unfortunately, this encoding relation breaks down as the magnification increases and the beam interaction volume on the sample becomes appreciably larger than the corresponding pixel size in the image (Fig. 1). The effective radius of the interaction volume, $r$ is about $40 \%$ of the electron range, $R=\mathrm{kV}_{0} 3 / 2$ (Joy, $1984 \mathrm{a}, \mathrm{b})$. Therefore, as $\mathrm{V}_{0}$ is reduced from $20 \mathrm{kV}$ to $1 \mathrm{kV}$, the radius of the beam interaction volume is reduced by $90: 1$ and topographic contrast increases. The possible effects of this increased contrast on image formation at high spatial resolution is only now beginning to be assessed (Boyes, 1984, Pawley, 1984a,b, Joy, 1984a,b).

Clearly, resolution in the secondary electron mode depends entirely on the size of the area sampled by the beam. This in turn depends on both the size of the probe and the scattering properties of the specimen.

Topographic Resolution/Contrast in the SEM

The detected secondary electron signal from a given pixel on the sample is a function not only of $\delta$ and the surface angle, but also of the a verage, $Z$, of the volume of beam penetration (Everhart et a1., 1959; Seller, 1976; Ball \& McCartney, 1981), the crystallographic orientation (LeGressus et al., 1983), the surface potential (Oatley \& Everhart, 1957; Oatley, 1969; Banbury \& Nixon, 1970; Pawley, 1972; Kursheed and Dinnis, 1983), the presence of nearby surface features which may affect the collection efficiency (Everhart et al., 1959; Pawley, 1972), the presence of second or third surfaces of the sample within the penetration volume from which additional electrons may be produced and collected (Wells, 1978), the efficiency with which high energy backscattered electrons are converted into collectable secondaries by collisions within the sample chamber (0atley et al., 1965; Reimer \& Volbert, 1979; Peters, 1982) and, finally, various arcane variables such as the presence of subsurface charge that may effect $\delta$ on uncoated insulators (Shaffner \& Hearle, 1976).

The complexity of the interaction of these variables as they affect the high magnification image of a typical sample is considerable and is perhaps the reason contrast and resolution in the secondary electron mode have been the object of so much research and interest, for example: Everhart et al., 1959; Oatley et al., 1965; Pease \& Nixon, 1965; Clarke, 1970; Oatley, 1972; Catto \& Smith, 1973; Wells, 1974a,b; Haggis \& Bond, 1979; Peters, 1979, 1982; Re1mer, 1978; Joy, 1984a,b).

The three main theoretical assumptions that have guided inquiries into topographic resolution in the SEM are: 1) That secondary electrons (0-50 $\mathrm{eV})$ are produced by inelastic collisions between electrons from the beam and those in the sample but that only collisions within a few $n m$ of the surface have any chance of producing secondaries 
that can escape and be collected. 2) That the local surface angle modulates the number of secondaries so produced in a way which produces an 1 mage that is easily interpreted by the brain as topography when the secondary electron signal is presented as an intensity-modulated image. 3) That while collectable secondary electrons are produced by beam electrons striking the sample (Type 1) or the objective aperture (Type 4 ) and also by backscattered electrons emerging from the sample (Type 2) or striking the specimen chamber (Type 3 ), only the Type 1 signal carries high resolution topographic information. (Several other minor electron currents are described by Oatley (1983.).

The distribution of secondary electrons leaving the sample as a function of the distance from the point of impact is assumed to have a small peak within a few $\mathrm{nm}$ of the beam axis and a long 'tail' extending many micrometers in all directions and corresponding to the probability of a secondary electron being produced by a reemergent backscattered electron (Joy, 1984a,b). For fairly high $V_{0}$, such a distribution has been directly observed by using the surface of a tilted SEM sample as the source of an emission microscope (Hasselbach \& Rieke, 1982; Hasselbach et al., 1983). In visualizing the relative dimensions of these two parts of the distribution, it is important to keep in mind the large magnitude of the difference between the range of a $20 \mathrm{kV}$ backscattered electron and a 4-50 eV secondary electron. On metal-coated, dried biological material (density $0.2 \mathrm{~g} / \mathrm{cm}^{3}, \mathrm{Z}=7$ ) the former may be $100 \mu \mathrm{m}$ and the latter $0.002 \mu \mathrm{m}$ (Joy, 1984a). To obtain high resolution topographical information it is necessary to somehow separate the relatively small peak signal (Type 1) from the much larger slowly varying signal produced by the tail (Types 2 and 3).

Initially, it was thought that this separation could be accomplished simply by raising the beam current and treating the tail signal as a DC noise signal that could be electronically removed by analog subtraction. This approach was not very successful, probably because of the difficulty of increasing the beam current in a small spot sufficiently and because, even though the average value of the $D C$ offset could be removed, the noise associated with statistical variations in the number of electrons that this signal represented could not be removed and soon this noise swamped variations in the Type 1 signal (Wells, 1974a and b).

To reduce the Type 3 and, to a smaller extent, the Type 2 signal, (Peters, 1982, Peters et al, 1983) has recommended placing backscattered electron absorbers below the polepiece and coating the surface of biological samples with very thin layers of low $Z$ metals. His results, using a field emission SEM at $30 \mathrm{kV}$ show a clear improvement over normal operation but the approach does not tackle the problem of removing the Type 2 signal very directly. On the other hand, Crewe and Lin (1976) recommended detecting the backscattered signal independently, using a semiconductor detector attached to the polepiece, and then subtracting some fraction of this from the signal derived from the normal scintillator-

photomultiplier detector. The logic is that the Type 2 and Type 3 signals should be proportional to the backscattered detector output and subtracting this from the normal detector output should leave only the Type 1 signal. As the backscatter detector used in this work covered about $\pi$ steradians, this is a reasonable analysis but the correspondence is not perfect because the detector has a large hole in the middle to allow the beam to pass through and the energy and angle of a backscattered electron may effect its chance of producing a collectable secondary in a way not proportional to the signal it produces in the semiconductor detector. Nonetheless, these authors also show a clear improvement (pp. 236) and the technique has been used by others (Volbert $1982 \mathrm{a} \& \mathrm{~b})$.

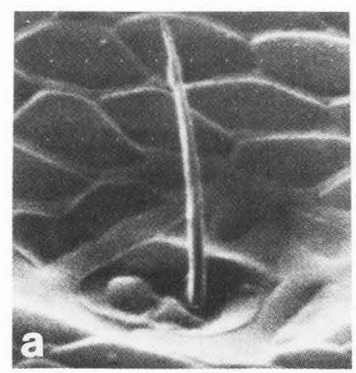

$2 \mathrm{kV}$

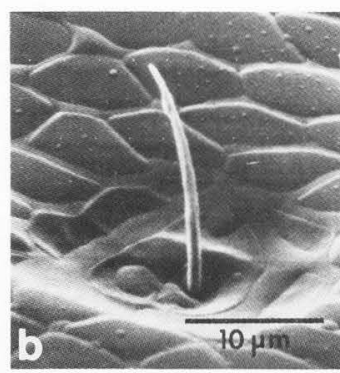

$5 \mathrm{kV}$

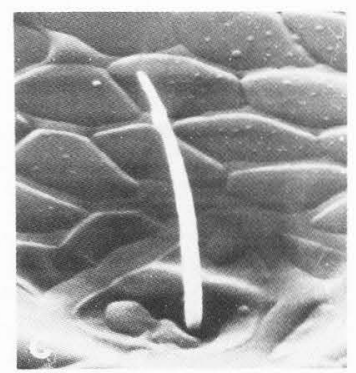

$10 \mathrm{kV}$
Figure 1: Three micrographs made with a 'conventional' SEM and showing a hair on a flour beetle which has been sputter-coated with gold and imaged with $V_{0}=2,5$ and $10 \mathrm{kV}$. In a, details on the surface of the hair can be seen and the near side is approximately the same shade of grey as comparably oriented surfaces on the bulk of the spe- cimen. In $c$, the hair appears much brighter than these adjacent areas because considerable signal is generated as the beam emerges from the far side of the hair and the coding of the image is no longer strictly topographic. Figure lb shows an intermediate condition. 
Finally, there is a large group of investigators who, untroubled by theoretical misgivings, have made images of a variety of samples that appear to demonstrate topographic resolution far in excess of that which would be possible if the Type 1 signal is indeed likely to be swamped by Types 2 and 3 . Some of these studies have used scanning attachments on the transmission electron microscope operated at (TEM/SEM) 20-80kV (Koike et a 1., 1971, 1973; Arro et a1., 1981; Haggis \& Bond, 1979; Haggis, 1982; Haggis et al., 1983). In the $\mathrm{TEM} / \mathrm{SEM}$, the sample is immersed in the lens field and the secondary electron signal consists of those electrons that spiral up the field lines and out through the upper pole piece. This process may preferentially exclude the Type 3 signal and definitely provides a distinctly different image of the sample than does a conventional detector (Buchanan, 1982, 1983). Other workers have utilized field emission SEMs (Lin \& Lamvik, 1975; Wa tabe et a1., 1978; Sawada, 1981; Peters et a1., 1983) which in some cases were modified to permit secondary electrons to be collected from a sample located in the lens field (Tanaka, 1980, 1981).

A third approach involves looking at what might be considered the inverse of the Type I signal, namely the signal derived from backscattered electrons that have only lost a small amount of energy in a glancing collision with a steeply tilted sample. This low-loss backscattered signal can be detected in a normal SEM with an appropriately placed backscattered electron detector (Wells, 1979) or from a sample immersed in the field of a short focal-length condenser-objective lens which also serves as an energy filter (Wells et al., 1973; Joy \& Maher, 1976; Kokubo et al., 1975). The latter method is capable of producing very high resolution images of metal-coated samples because electrons that have lost only $200-400 \mathrm{eV}$ have only participated in interactions near the sample surface (Broers et al., 1975). Topographic or $Z$ contrast?

It is not clear that any of these signals is really a topographic signal rather than a $\mathrm{Z}$ signal that chiefly responds to variations in the granularity or the effective thickness of the metal coating on such samples and is further modified by differences in the signal collection efficiency from point to point on the sample (Fig 2). In fact Wells points out that a layer of carbon contamination, artificially produced to cover the surface of such a sample, is barely visible using the low loss mode (Wel1s, 1979, pp. 213). A similar lack of fine detail on flat surfaces can be seen in the images of carbon black particles shown in the TEM/SEM by Koike et al. (1973). Though these images appear to be topographic, they are not topographic in the same sense as is the case at low magnification. They may indeed provide useful information about the sample, but it is important to realize that they are in fact analogous to TEM images of shadowed replicas and should likewise be viewed with caution. They may, for instance, reveal more about the nucleation of metal particles than they do about sample topography and they discriminate against small features on flat surfaces and in favor of similar features suspended over the cavities.
Our acceptance of $\mathrm{Z}$-contrast images as 'topographic' can be traced to the need of manufacturers to demonstrate real improvements in instrument performance. In the early 1970's resolution in images made using the signal from the secondary electron detector fell below about $20 \mathrm{~nm}$ and the criterion ceased to be the smallest discernible surface object and became instead the smallest discernible object. Subsequently, the probe diameter was greatly reduced and the test objects were chosen to demonstrate this improvement, rather than to demonstrate that smaller surface features could be resolved (Ballard, 1972). As a result the 'resolution' in the secondary electron mode is now of ten quoted to be 1.5-3 nm while the best results show images of biological objects such as intermediate filaments and ribosomes in the size range of 10-25 nm (Tanaka, 1981; Haggis, 1982; Haggis et. a1., 1983; Peters, 1982; Peters \& Green, 1983).

Many popular test objects can be modelled as a series of heavy metal particles covering the surface of a low $Z$ substrate such as a carbon film or a dried biological sample. In this case, the main contrast is $Z$ contrast, either between high $Z$ metal grains and low $Z$ inter-grain spaces, or, in the case of uniform coating on a bumpy surface, variations in the effective thickness of this coating as the beam traverses the coating at different angles. On a highly convoluted surface, this signal may also reflect variations in coating thickness and the large variations that exist in the efficiency with which electrons emerging from a given area are collected. These effects are diagrammed in Fig. 2 which shows a hypothetical coated surface and a corresponding image shaded solely in response to changes in effective coating thickness.

The problem of low contrast can also be approached by reducing the beam voltage as suggested by many early authors (Thornley, 1960; Kosuge et a1., 1970; Boyde, 1971; Catto \& Smith, 1973; Welter \& Coates, 1974; Wells, 1974b pp. 127; Dilly, 1980). At $V_{0}<10 \mathrm{kV}$ there is a sharp increase in Type 1 signal (Joy, 1984a). In addition $R$ at $1 \mathrm{kV}$ is only about $2 \%$ of that at $20 \mathrm{kV}$ and so the area of sample from which Type 2 secondaries are produced is 2500 times smaller. As the backscatter coefficient diminishes only slightly with voltage (Niedrig, 1978; Reimer, 1979, Fig. 8; Kotera et al., 1981), the number of Type 2 electrons may still be significant but they will emerge from a smaller area. There have been few attempts to produce high resolution SEM images using beam energies near $1 \mathrm{kV}$ because of the electron-optical constraints mentioned in the Introduction and discussed in the next section, so it is still not certain that, on the finest scale, LVSEM has a clear advantage. On the other hand, results at somewhat lower resolution show a clear increase in the contrast of small details (Fig. 3) and so there is reason to expect that the same will hold if LVSEMs with smaller probes can be made.

An analysis of the effect of $V_{0}$ on high resolution topographic contrast at present depends on estimates of how $V_{0}$ affects the modulation of Type 1 electrons by the local surface angle and how it 
(2) EFFECT OF COATING ON HIGH RESOLUTION TOPOGRAPHIC SIGNAL

a)

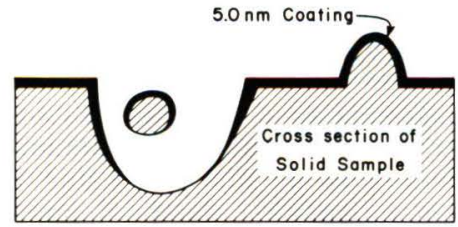

b)

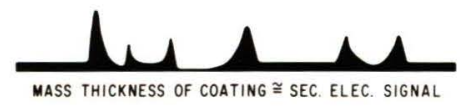

C)

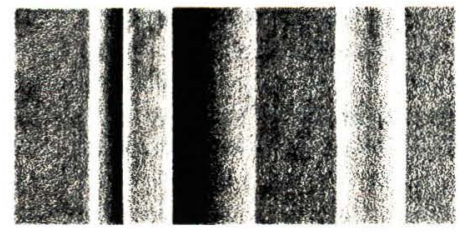

IMAGE
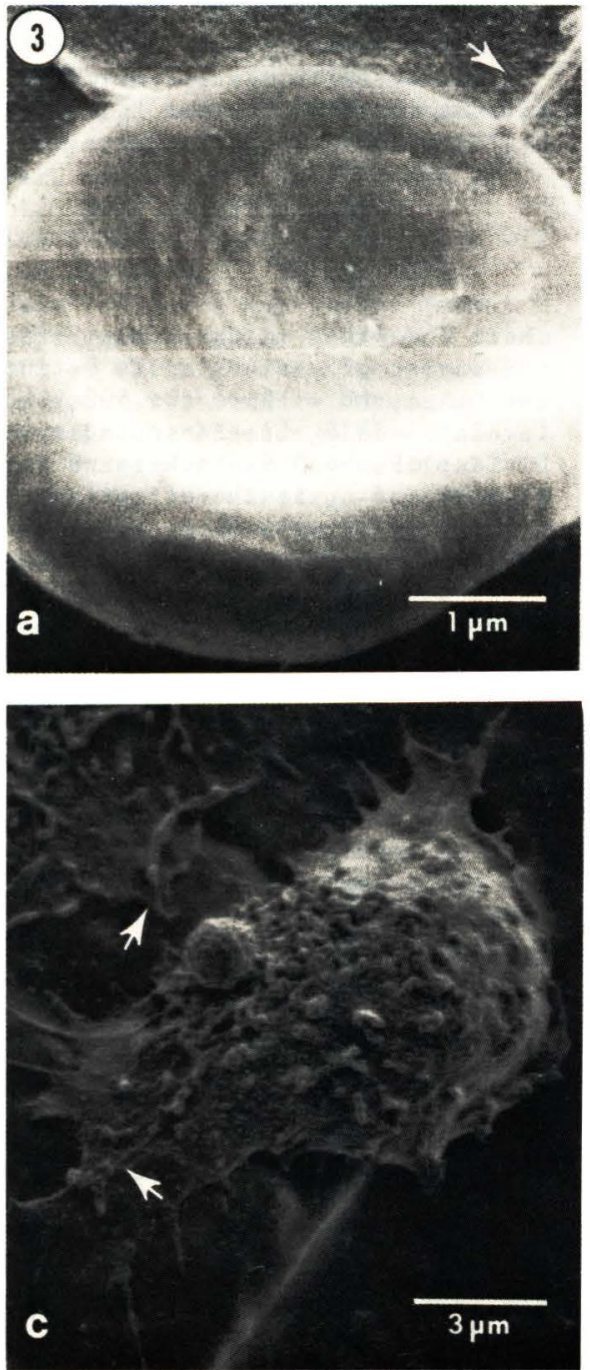

$1 \mathrm{kV}$
Figure 2: Coating thickness contrast: a) crosssection through a rough surface that has been metal coated is shown schematically, b) the effective thickness of this coating as a function of position, c) what appears to be a topographic image of an extended specimen having the cross-section shown in a. It results from coding image lightness as being proportional to coating thickness rather than surface angle. (The image may be more easy to interpret if viewed from a distance.)

Figure 3: Critical point dried blood cells on a grid covered with a thin film, coated with carbon and imaged at $1 \mathrm{kV}(\mathrm{a}, \mathrm{c})$ and $20 \mathrm{kV}(\mathrm{b}, \mathrm{d})$ in a FE SEM. The upper pair clearly shows the loss in contrast of small surface detail in the background film (arrows) and on the surface of a red blood cell. In the lower pair the cells are located over a grid bar which produces a considerable background signal at the higher voltage. Again small surface details are more visible at the lower voltage (arrows) as are details on the ruffles on the surface of this platelet. (Sample kindly provided by Dr. E. de Harven).
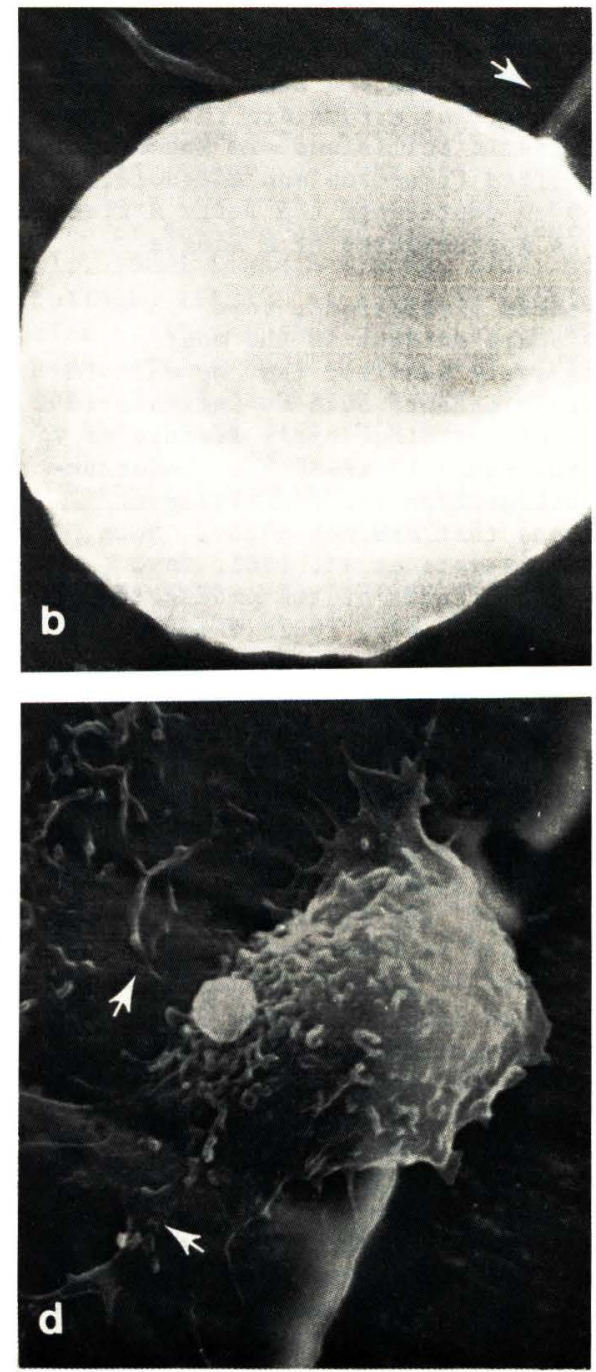

$20 \mathrm{kV}$ 
effects the relative strengths of the four types of detected signal. Because there is a lack both of sultable test objects and of probe forming columns with the necessary capabilities, such analyses typically involve the use of Monte Carlo techniques to simulate the scattering interactions of a beam as it passes over a homogeneous surface having some analytically simple topographic feature such as a cube (George and Robinson, 1975) or a gaussian asperity (Catto and Smith, 1973). To increase computational speed, Monte Carlo methods greatly simplify the interactions between the beam and the sample. They usually consider only the uncontaminated surface of a homogeneous (non-crystalline) metallic object and assume that both elastic and inelastic collisions are highly locallzed. They usually ignore a host of other interactions, such as those producing X-rays, Auger electrons and other characteristic interactions, even though these interactions may produce other collectable secondaries from remote locations. Finally, as the rate of energy transfer increases strongly when the electron slows down near the end of its track, the last 200-500 eV is usually modelled as being deposited in a single point. When these simplifying assumptions are used to estimate contrast on the size scale of $\mathrm{nm}$ with $\mathrm{V}_{0}=1 \mathrm{kV}$, important errors are introduced. For instance, inelastic collisions are known not to be highly localized (Isaacson and Langmore, 1974) and 200-500 eV represents too large a fraction of $\mathrm{eV}_{0}$ to be approximated by a single event.

In spite of these $11 \mathrm{mitations,} \mathrm{some}$ interesting trends are evident in the most complete of these early studies, that by Catto \& Smith (1973). These authors note an increase in the size of the smallest discernible feature as $V_{0}$ is increased in the range $10 \mathrm{kV}-30 \mathrm{kV}$. Unfortunately, they do not continue their analysis to lower $v_{0}$ for reasons that are not clear. More recent simulations (Murata et a1, 1981, Joy, $1984 a, b)$ include the effects of the production of fast secondaries (Joy et. al., 1982) which may have energies up to $\mathrm{eV}_{\mathrm{o}} / 2$ and can therefore excite additional low energy secondaries along their tracks. Though not produced in great numbers, they are important because they of ten travel almost perpendicular to the primary beam and therefore produce secondaries at some distance from the probe. Figure 3 from the $1984 \mathrm{~b}$ paper by Joy shows secondary emission vs distance from the axis for 2,5 and $30 \mathrm{kV}$, and is reproduced here as Fig. 4a. The intensity in electrons is normalized to the number produced at a given voltage on axis. While all three curves drop to $\sim 25 \%$ by $2 \mathrm{~nm}$, they have distinctly different shapes beyond this distance. In particular, the intensity of the Type 2 signal (i.e. that emerging more than $2 \mathrm{~nm}$ from the axis) appears to be substantially higher at the lower voltages, implying a reduction in topographic contrast at lower $V_{O}$. This is not actually the case because 1) The graph is 100 times too small on both axes to show the full curve for $30 \mathrm{kV}$ while it does show the $2 \mathrm{kV}$ curve out almost to the edge of the interaction radius, $r$. In figure 4b the same data has been extrapolated to the larger size range. Although these curves only represent an estimate of the probable shape and should not be taken as hard data, they do emphasize the fact that the central peak in the distribution does sit on a large iceberg of poorly localized emission. If the curves were plotted for dried biological tissue (density $=0.2 \mathrm{~g} / \mathrm{cm}^{2}$ ) rather than for solid carbon, the distance scale would be expanded by a further factor of 10 . Each distribution has been normalized at its maximum, and therefore no allowance has been made for the increase in total $\delta$ at the lower voltages.

If the curves in $4 \mathrm{~b}$ were more accurate, we would integrate the signal under the curve in two regions: the local region up to $2 \mu \mathrm{m}$ and the nonlocal region beyond this distance. It seems likely that the ratio of local to non-local signal might be 5-6 times higher at $2 \mathrm{kV}$ versus $30 \mathrm{kV}$.

This difference represents a potential increase in detectable topographic contrast and it has some interesting consequences. As $V_{0}$ is reduced from $20-1 \mathrm{kV}, \delta$ (normal incidence) increases from 0.1 to $\sim 1$ and therefore generally recognized that, the beam current $\left(\mathrm{I}_{\mathrm{b}}\right)$ required to produce an image of a given quality is correspondingly reduced by a factor of 10 . However, the effect of increased contrast on the required current is usually not specifically considered.

Wells (1974b eq. 2.2 lb) calculated the relation between required current $I_{b}$ and signal contrast $\left(s_{a}\right)$ for low contrast objects as:

$$
I_{b}=K \frac{\delta_{b}}{\delta_{a}{ }^{2}}
$$

where $K$ depends on the raster size, recording time and number of statistically defined grey levels in the image, ( $\mathrm{K} \simeq 10^{-12}$ for $500 \times 500,100 \mathrm{sec}, 10$ levels), and $\delta_{b}$ is the secondary electron coefficlent of the D.C. background signal (the 'black' signal) and $\delta_{a}$ is the effective contrast of the normalized signal, (i.e. the peak signal minus $\left.\delta_{b}\right)$. This equation includes the assumption that $\delta_{b}>\delta_{a}$ and this is true for small surface features seen at high magnification. Equation 1 is important to an analysis of the LVSEM because it shows that the required current depends directly on the DC offset of the signal and inversely with the square of the contrast. At low Vo both of these quantities change so as to reduce the beam current required to produce an image of a given quality. This is important because, as we shall see below, gun brightness is significantly reduced at low beam vol tage.

\section{Specimen Charging in the LVSEM}

Many objects of microscopic interest are electrical insulators. When the surface of such a sample is scanned by a 1-30 kV electron beam, collisions in the layer immediately adjacent to the surface cause it to become somewhat depleted in electrons, while the next layer immediately below becomes negatively charged because beam electrons are trapped as they reach the end of their range. The deposition of a net charge in the sample depends on $\delta$, which in turn depends on the type of material, and the local surface angle. (at glancing incidence $\delta$ can be as much as 4 at 20 $\mathrm{kV}$. Pawley, 1984b). Around 10-30 kV, $\delta$ for most samples is less than unity and the sample accumulates a negative charge which may degrade the 


\section{Low Voltage Scanning Electron Microscopy}

image by defocusing the beam or by distorting the collection field so as to produce the anomalous changes in apparent brightness familiar as the most common form of charging artifacts (Pawley, 1972). As higher surface potentials are reached ( $>10^{\prime} \mathrm{s}$ of volts), other, more extreme phenomena are recorded as described by Shaffner \& Hearle (1976). Other variables that exacerbate the charging problem are high specimen resistivity (so-called insulators vary in resistivity over a range of 15 orders of magnitude), low specimen dielectric constant and slow scan speeds (Welter \& McKee, 1972).

The situation is somewhat different in the LVSEM because on a variety of samples $\delta$ at normal incidence becomes greater than unity in the range of approximately .5 to $3 \mathrm{kV}$ and so the sample charges positively. This is a far more stable situation because low energy electrons are constantly being evolved from the surface and so even a small positive charge imbalance can attract an appropriate neutralizing charge without the necessity of developing a surface potential higher than a few hundred millivolts. Because this selfregulating process is so efficient, it is often claimed that charging artifacts do not exist when $\delta>1$ and the rapidity with which TV-rate images of such samples stabilize is offered as proof of this contention (Welter \& McKee, 1972). However, this analysis is only strictly true for the trivial case of a flat, featureless sample with $V_{0}$ adjusted for $\delta=1$. More topographically interesting samples show contrast and hence, $\delta=1$ cannot be satisfied everywhere. In practice, areas where the beam incidence approaches normal may become slightly negative while areas of glancing incidence, or where the beam penetrates porous surface features will tend to become positive. Lateral electrostatic fields will exist between neighboring charged areas and vertical fields will exist between the electron-depleted surface layer and the trapped charge below. A small amount of current flows between these areas using free subsurface electrons, ionized by the beam, as charged carriers (Bresse, 1982). Clearly the situation is far more complicated than is implied by the simple statement that there are no charging artifacts whenever $V_{0}$ is set so that $\delta \geq$

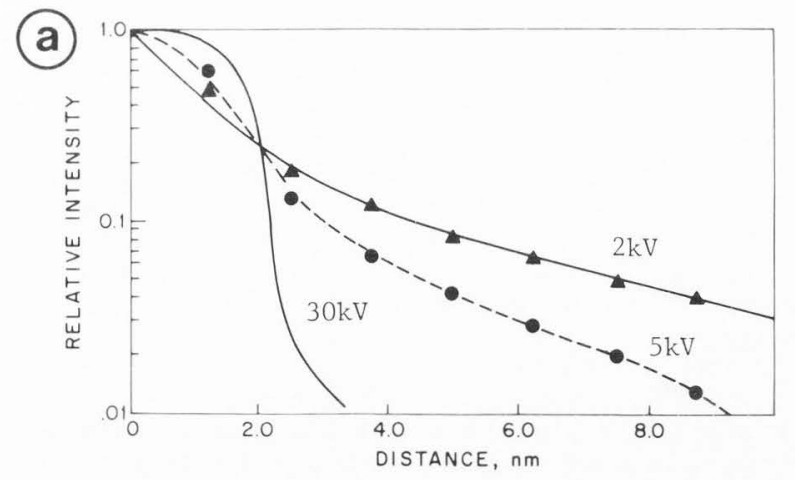

Figure 4: a) Normalized intensity of secondary electron production from carbon as a function of distance from the point of impact at 2,5 and 30
1. The stability of an image scanned at TV rate is only evidence that a particular charge distribution is stable, not that there is an absence of charging.

The details of this process are of interest here because they involve the establishment of surface and subsurface potentials which, though small when compared to those found with higher $v_{0}$, may still be capable of defocusing or deflecting a beam of only $1 \mathrm{kV}$ and thereby degrading the image. Surface potentials of the same size as $\Delta \mathrm{V}(0.2 \mathrm{~V}$ for FE guns) will defocus the beam and even smaller potentials could deflect it a few $\mathrm{nm}$, perhaps in an erratic manner. In fact some investigators claim less trouble with charging at high voltage in the TEM/SEM than at lower voltages in the SEM (Haggis, 1982). This can be attributed to increased beam-induced conductivity at higher $\mathrm{V}_{O}$ and to the partial immunity of the TEM/SEM detector to voltage contrast.

At present, the magnitude of these effects has not been investigated in the range of resolution and $V_{0}$ discussed here. It can be expected that when $V_{0} \cong 1 \mathrm{kV}$, charging effects on insulating samples scanned at TV rates should be insufficient to produce large variations in signal collection efficiency, but not that they will be totally absent. Very thin $(1-1.5 \mathrm{~nm})$ layers of coating material such as those used by Peters (1979, 1982) may be necessary. Fortunately, the procedures for applying these coatings have greatly improved in the past few years particularly with the introduction of ion-gun based sputter sources (Adachi et a1., 1983; Evans \& Franks, 1981; Kemmenoe \& Bullock, 1983). As a result problems with decoration artifacts should be less common and the pseudo-topographical contrast caused by the coating and discussed above, should be minimized by the use of very thin coatings.

\section{$\frac{\text { Technical Limitations and Possible Solutions }}{\text { in LVSEM }}$}

The technical difficulties that must be overcome in order to produce high resolution information from an LVSEM are similar to those noted for the low voltage TEM by Wilska (1964, 1965).

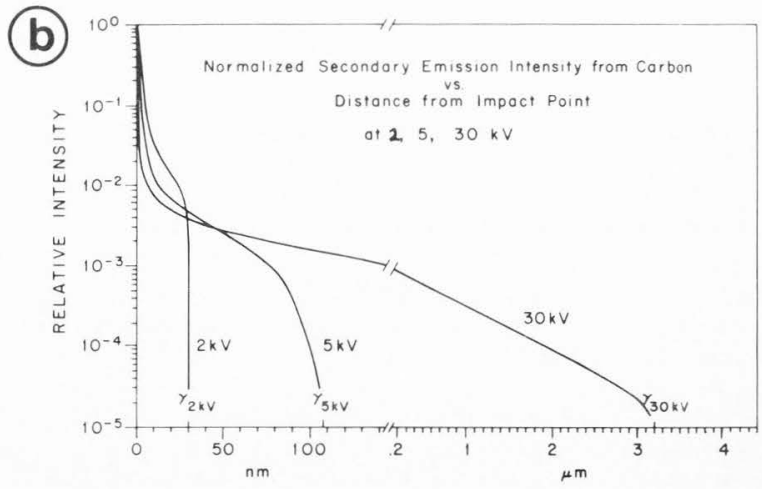

$\mathrm{kV}$ (from Joy, 1984a). b) the same data as in a), extrapolated to the total emission range at each voltage and plotted on different scales. 
They were first 1 isted for the SEM by Oatley et a 1. (1965, p.215-217). They can be lumped into four areas: 1) low source brightness, 2) increased effect of chromatic aberration, 3) increased susceptibility to stray fields, 4) interactions between the beam and the signal collection field. Though these problems and their solutions sometimes interact, they will be treated separately below.

Brightness of Thermionic Sources at Low Voltage

It was early recognized that source brightness was the practical limit on the performance of an SEM with a heated tungsten source (Broers, 1974, 1982). In principle, the effect of spherical or chromatic aberration on spot size can be minimized by reducing the acceptance angle of the final lens, $\alpha$, until the lens becomes diffraction 1 imited. However, in instruments with conventional tungsten sources, the image becomes too nolsy for convenient use long before $\alpha$ is reduced to the diffraction limit.

The brightness ( $\beta$ ) of a thermionic electron source is limited by the Langmuir Equation (Langmuir, 1937) for small $\alpha$.

$$
\beta=j_{0} \frac{(11,600)}{\pi T} v_{0} \text { amps } / \mathrm{cm}^{2} \text { ster }
$$

Where $j_{0}=$ current density at the source surface in amp/ $\mathrm{cm}^{2}, T=$ source temperature in ${ }^{\circ} \mathrm{K}$, and $\mathrm{V}_{\mathrm{O}}$ = beam vol tage in volts.

From equation 2 it follows that low $V_{0}$ operation will produce reduced brightness. In practice the brightness actually obtained is even lower than we might expect from (2) because this equation is only valid in the absence of space charge near the cathode surface. Such space charge shields the cathode from the accelerating field and further reduces $\beta$. Though a given gun geometry may be virtually free of space charge effects near its highest operating voltage (20-30 kV) (Broers, 1974; Oatley, 1975), the flelds present at the filament surface are proportionately less at $1 \mathrm{kV}$ and the gun brightness will be limited by space charge unless the geometry is changed.

Practical measures to improve thermionic gun brightness at low $\mathrm{kV}$ therefore include changing gun geometry and the use of $\mathrm{LaB}_{6}$ cathodes. The latter have a brightness about 6 to 10 times that of tungsten for comparable lifetime, a tip which is more pointed and which reduces the effect of space charge and operates at a lower temperature than normal tungsten $\left(\mathrm{T}=1800{ }^{\circ} \mathrm{K}\right.$ vs 2700 ${ }^{\circ} \mathrm{K}$ ). Changes in gun geometry may involve simply reducing the gap between the Wehnelt and the anode by using an anode spacer or a mechanism to actually move the anode towards the cathode or it may involve adding additional anodes to the gun. A description of this 'double-anode' approach was recently given by Yamazaki et al. (1984). This group installed extraction anodes of various shapes and spacings between the Wehnelt and the normal anode. At low $V_{0}$ this electrode is run a $f$ ew $\mathrm{kV}$ above ground to produce a higher constant voltage between $i t$ and the cathode $\left(v_{1}\right)$ and thereby reduce the effects of space charge.

Careful measurements verified that, at 1 and 2 $\mathrm{kV}$, this produced 10 times the brightness of a normal $30 \mathrm{kV}$ gun with tungsten and eight times the brightness with $\mathrm{LaB}_{6}$. They reached the theoretical brightness specified by equation 1 at both these voltages using their best geometry, which is diagrammed in Fig. 5. Al though it is not specifically pointed out in their paper, the acceleration/deceleration electrode system acts as a weak positive lens and this is probably why these workers found that $\beta$ went through a maximum at $v_{1}=1.5 \mathrm{kV}$. The effect of this lens on the imaging system was unclear but in images of a test sample, a distinct improvement was associated with the use of the double-anode system.

Brightness of Field-Emission Sources at Low Voltage

Field-emission (FE) sources have long been identified with high brightness (Crewe et al., 1968, 1970; 1971; Crewe, 1973; Hainfeld, 1977 has a good introductory review), but few commercial instruments have capitalized on this feature because of the stringent requirement for vacuum in the range of $10^{-8} \mathrm{pa}\left(10^{-10}\right.$ torr) around the emitter tip and because the current produced in a fine beam is subject to some temporal instability which tends to produce streaky images (Tuggle \& Watson, 1984; Orloff this volume). Most FE sources utilize a double anode design. The $V_{1}$ is normally 3 to $7 \mathrm{kV}$ and is used to adjust beam current, which is otherwise only dependent on the work function, $\phi$, and the tip radius, $r_{0}$. A second supply between ground and the cathode adjusts the beam voltage $\left(v_{0}\right)$ to the desired level and, in the case of the LVSEM, this means reducing 1 t and thereby again producing an electrostatic lens.

In principle, the geometric parameters can be adjusted so that the tip emits efficiently with $v_{1}$ $=1 \mathrm{kV}$. This would make the second anode unnecessary and avoid the consequent lens action. However, in practice, tips with sufficiently small $r_{0}$ usually prove unstable and subject to catastrophic fallure while a suitable cholce of the spacing and shape of the two anodes can reduce the lens effect to a low level.

In the range of voltages discussed here, the brightness of the source depends only on $v_{1}$ and not directly on $V_{0}$ except to the extent that the lens effect degrades the source image (Hainfield, 1977).

$$
\beta=\frac{a v_{1}{ }^{3}}{\phi r_{0}^{2}} \exp \frac{\left(-b r_{o} \phi^{3 / 2}\right)}{v_{1}}
$$

Where $a$ and $b$ are constants $\left(a=8.7 \times 10^{-8}, b\right.$ $\left.=2.1 \times 10^{8}\right)$. Several FE guns have been designed to incorporate a magnetic lens which operates on the beam as it leaves the tip (for example Kuo \& Siegel, 1976; Ichinokawa et al., 1982). These lenses have superior electron optical characteristics to the electrostatic lenses and are said to produce improved performance especially when operating at high current and low beam voltage. However, because of their high current these guns are more susceptible to the lateral electronelectron interactions discussed below and so it is not clear they would be suitable to high resolution LVSEM. 
Measurements with $\mathrm{V}_{1}=3 \mathrm{kV}, \mathrm{V}_{2}=1 \mathrm{kV}$ have yielded values of $\beta=3-70 \times 10^{6} \mathrm{amp} / \mathrm{cm}^{2}$, ster or about 1000 times that measured by Yamazaki et a1. (1984) on the $\mathrm{LaB}_{6}$ double-anode gun.

Al though there are reports that electronelectron interactions within the beam can degrade the expected performance of $\mathrm{FE}$ guns both in terms of reducing the brightness and increasing the effective energy spread (Bauer \& Speidel, 1981; Van Der Mast, 1983) these effects seem to be most serious on heated $\mathrm{FE}$ sources, sometimes referred to as Schottky or TF guns and hence the total beam current, unless the emitting area, can be restricted (Orloff, this volume). This effect is less serious on room temperature FE guns operated at moderate tip currents of about $10 \mu \mathrm{A}$. Other workers have observed no such effects as long as high current density crossovers are avoided (Crewe et al., 1971). Clearly the electron-electron interactions near the cathode surface are reduced by the fact that the $F E$ cathode has a tip radius 20-50 times smaller than $\mathrm{LaB}_{6}$. This subject is considered further in the next section. Noise in FE Sources

If the current present in the final beam of a high resolution FE SEM is traced back to the tip, it is found to arise from an area of only a few $\mathrm{nm}^{2}$. The adsorption and desorption of individual molecules from this small surface can therefore produce a significant variation in its average work function while the etching produced by the collision of a single ion can change the microtopography and hence the local surface field. As a result, the current in the final probe is found to have a noise component unrelated to shot noise of between 3 and 10\% (Hainfeld, 1977).

This noise drops in magnitude with increasing frequency and therefore is most troublesome at low frequencies. Efforts to stabilize the beam current by measuring the current striking an aperture and using this as a feedback signal to readjust $v_{1}$ (Nomura et al., 1973) are quite effective but not wholly successful because, due to the localized nature of the disturbance at the tip, the current striking the aperture is not necessarily a good measure of the current passing through it. Also, the changes in $V_{1}$ necessary to $s$ tabilize the current change the optical properties of the electrostatic lens. More recent systems avoid this optical effect by applying the signal from the aperture to an analog multiplier which directly normalizes the video signal for changes in beam current (Saito et al., 1982).

Another approach involves rapid, multiple scanning of the sample with the idea that low frequency variations will average out (Welter \& Mckee, 1972). The TV scan rate has other advantages with respect to ease of operation, stabilization of charging artifacts and quasi-immunity to stray field but it requires very high detector bandwidth ( $40 \mathrm{MHz}$ for a $1000 \times 1000$ raster, $1 / 30$ sec.) and careful scan coll design to avold image distortion.

The matter of source noise can be crucial to the final performance of a high resolution LVSEM. There will be little net gain in contrast by going to lower $V_{0}$ if the improved contrast at the sample is swamped by false contrast due to source instability. It is possible that this limitation lead to further consideration of the $\mathrm{Zr} / \mathrm{W}, \mathrm{TF}$ source developed by Orloff et al and described elsewhere in this volume.

Electron Optics for the LVSEM

Figure 6 shows effect of diffraction and spherical and chromatic aberratifon on attainable probe diameter for a 'conventional' SEM operating at $20 \mathrm{kV}$ and an SEM operating at $1 \mathrm{kV}$ using a lens having aberration constraints typical of a high quality TEM. In both cases the dominant lens defect is chromatic aberration. The diameter of the disk of confusion due to this defect, $d_{c}$, is:

$$
\mathrm{d}_{c}=\mathrm{c}_{c^{\alpha}} \frac{\Delta \mathrm{V}}{\mathrm{v}_{0}}
$$

where $C_{c}$ is the chromatic aberration coefficient and $\Delta V$ is the energy spread of the beam. Clearly, $\Delta V / V_{0}$ increases rapidly at 1 ow $V_{O}$, hence the problem. It can be attacked by lowering $C_{c}, \alpha$, or $\Delta V$. Lenses $c$ an be designed to reduce $C_{c}$ by shortening their focal length. While it is relatively easy, in terms of the total magnetic flux required, to construct a lens of short focal length at this low energy, the sample is soon immersed in the lens field so it may become more difficult to collect the secondary electron

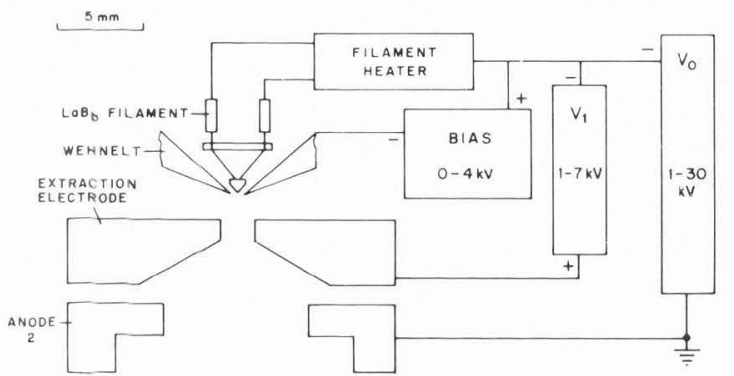

Figure 5: Double anode system for improved brightness from thermionic cathodes at low kV (after Yamazaki et al., 1984).

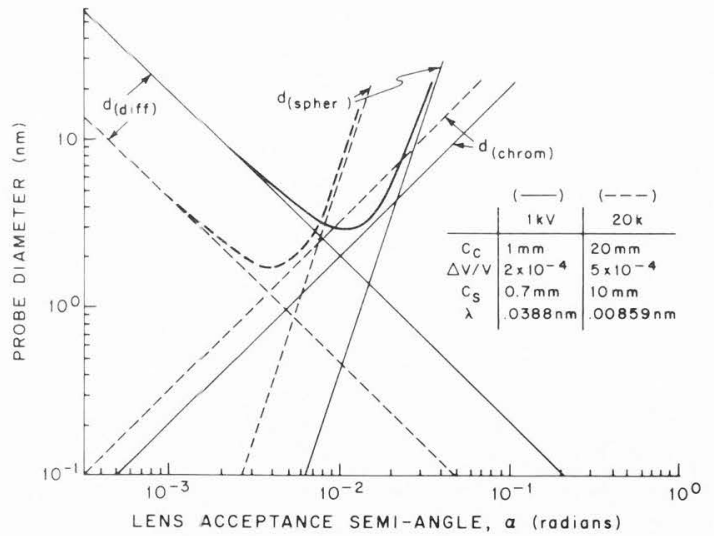

Figure 6: Electron optical limits to resolution in the conventional SEM at $20 \mathrm{kV}$ (dotted) and in a theoretical SEM using a low aberration lens similar to that used in a modern TEM but operating at $1 \mathrm{kV}$. Diffraction and spherical and chromatic aberration are the only limits considered. The smaller spot size minima are found to be both fairly similar and smaller than the size of actual biological objects that can be imaged at present in the SEM. 


\section{James B. Pawley}

signal. At the ultimate, it would probably be very difficult to design a practical system where $\mathrm{C}_{c}$ was much less than $0.2 \mathrm{~mm}$, (Pawley \& Wall, 1982; Barth \& LePoole, 1976). This compares with the 5 to $10 \mathrm{~mm}$ found on most commercial instruments and the 1-3 mm found on some sample-1n-1ens SEMs (Koike et al., 1971; Buchanan, 1982).

The semi-angle, $\alpha$, can also be manipulated, but because of the relatively long wavelength, $\lambda$, of $1 \mathrm{kV}$ electrons ( $37 \mathrm{pm}$ ), the diffraction limit, $d_{d}$, is soon reached.

$$
\mathrm{d}_{\mathrm{d}}=\frac{0.6 \lambda}{\alpha} \text { or } \frac{0.02 \mathrm{~nm}}{\alpha} \text { at } 1 \mathrm{kV}
$$

Finally, there is some control over $\Delta \mathrm{V}$. The energy spread of the beam has many sources: the intrinsic energy spread of electrons leaving the cathode, power supply instabilities and energy broadening caused by lateral electron-electron interactions in high-current crossovers known generally as the Boersch effect (1954).

The expected energy spread at the cathode surface for thermal emitters is $\mathrm{kT}$ and this again emphasizes the advantage of $\mathrm{LaB}_{6}$ vs tungsten because of $i$ ts lower operating temperature ( $\mathrm{kT}=$ $0.13 \mathrm{eV}$ vs $0.2 \mathrm{eV}$ ). Intrinsic energy spread in FE sources depends on the shape, the tip material and the crystallographic orientation of the tip but it is usually quoted as about $0.2 \mathrm{eV}$ for tungsten (Crewe et a 1., 1971; Hainfeld, 1977).

Lateral interactions between electrons are more noticeable when high current beams must form crossovers and this is often the case in thermal sources where large beam currents are often a byproduct of efforts to increase $\beta$ by reducing the effect of space charge (Oatley, 1975). The problem is compounded by the fact that this large current is usually focussed into a small gun crossover by the effect of the Wehnelt. Under these circumstances, a considerable improvement can be gained by employing pointed cathodes as these permit a high extraction field over only a small emitting area and therefore a lower total current (Wiesner, 1973; Wiesner \& Everhart, 1973; Ohshita et a1., 1978). Measured values of $\Delta V$ from thermal sources usually average about 2 to $4 \mathrm{eV}$ but the measurements are usually made at voltages much higher than $1 \mathrm{kV}$, where the Boersch effect is likely to be less strong because the electrons move faster and therefore have less opportunity to interact (Pfeiffer, 1972, 1982).

The $\mathrm{FE}$ and $\mathrm{TE}$ guns have clear advantages in this regard. They not only have low intrinsic energy spread but they can operate well at low total beam currents and because of their small virtual source size they can, in principle, operate with no crossover before the sample. Taken together with the higher brightness of $\mathrm{FE}$ and $T F$ at $10 w \mathrm{kV}$, the reduced energy spread provides a convincing rationale that any serious effort to produce optimum performance in the LVSEM will necessarily require elther a $\mathrm{FE}$ source and a method for compensating for its temporal instability or a TF source.

Stray Fields

A $1 \mathrm{kV}$ electron takes 5 times as long to travel down a given column as does a $25 \mathrm{kV}$ electron. For this reason, in simple terms, it is 5 times as susceptible to transverse stray electrostatic or magnetic fields. This effect is sometimes exaggerated on large, older instruments because they are often run with less demagnification in the intermediate lenses to compensate for low source brightness and as a result, stray fields acting on the upper column, which usually have no visible effect, begin to be noticeable. Field emission systems are similarly susceptible because they normally operate with little or no demagnification.

Both $A C$ and DC electromagnetic fields can degrade the performance of electron optical instruments. DC magnetic fields are produced by 1 on pumps, lenses, the earth and any stray ferromagnetic materials that may have been built into the apparatus by mistake. Usually their only effect is to cause misalignment between the mechanical and the electrical axis of the instrument but they can also be responsible for saturating high permeability shielding materials, thereby rendering them ineffective for shielding AC fields. At low voltage, stray electrostatic fields can also be very troublesome. Any insulator which can be encountered by the beam will develop a surface charge and this charge will in turn produce a field that deflects the beam. To avoid this, the column must be designed so that a 11 insulators are shielded from the beam and great care must be taken to exclude even the most minute particles of dust or lint from the apparatus. Even the choice of materials is important because many metals commonly used for high vacuum applications such as stainless steel, Mo, T1 and Al are normally covered with a layer of nonconductive oxide. The effects of surface charge accumulation on many of the metals used in electron microscopy is well described by Anger et a 1. (1983). Particular attention should be given to the fabrication of beam tubes and apertures and these should probably be made of acid-cleaned Pt.

Although there are instances of electrostatic pickup from nearby radio stations producing noise in the scanning circuits, most AC fields of interest to the microscopist are magnetic and are linked to the mains frequency. Their effect can be reduced by synchronizing the scan frequency to the mains which has the effect that the stray field becomes an image distortion rather than a blurring function. Even so, stray AC magnetic fields remain one of the most persistent practical problems associated with operating the SEM at low voltage, especially when small-area, rapid-scan rates are used for focusing and astigmatism correction. To avoid them, great care must be taken in selecting the installation site, in making the column as short as practical and shielding it with several layers of high permeability magnetic materials, especially the gun region and the sample chamber. Several small commercial FE SEMs have been entirely enclosed in a box of shielding material. In addition, it is necessary to ensure that no stray fields are introduced to the column by currents flowing in ground loops through the equipment or by ripple on supplies feeding the scanning, stigmator or alignment coils or the field used to collect the signal electrons. These stray currents may be insignificant when the instrument operates at high voltage and only become noticeable when the magnitude of 
the current in the deflection coils is reduced to operate at low voltage.

The ability to detect and eliminate stray fields is crucial to successful operation of the LVSEM, but unlike the design of the microscope column, it is at least in part susceptible to improvement by the efforts of a well-informed operator. The techniques by which this may be done are discussed in more detafl elsewhere (Pawley, 1984c).

Problems of Signal Collection in the LVSEM

In most SEMs, secondary electrons produced by collisions between the beam electrons and the sample are collected by a field imposed by a grid at about +300 volts, which attracts electrons to the entrance of the scintillator/photomultiplier signal amplifier (Everhart \& Thornley, 1960). This works well when the sample is 5 to $10 \mathrm{~mm}$ below the objective lens pole-plece, but as the working distance is reduced in an attempt to dimi$n$ ish $C_{c}$, the same horizontal field at the sample surface becomes less efficient at collecting signal electrons. On the other hand, this field becomes relatively large compared with the beam energy and it therefore can produce some distortion of the beam.

There have been four strategles to overcome this problem. The simplest is to use an objective lens with a sharply conical lower pole-piece which permits the collection field to penetrate to the electron optical axis more easily (Nakagawa et a 1., 1982; Pomposo and Coates, 1982). This approach also permits observation of large highlytilted flat samples but it has the disadvantage that conical lenses of ten have reduced electron optical properties due chiefly to flux leakage in the region where the conical pole-pieces taper together. The second method is to use the signal collection system employed in the TEM/SEM where the sample is immersed in the lens field and the low energy electrons spiral up the field lines through the hole in the upper pole-piece where they are then collected by a small transverse electric field (Kolke et al., 1971, 1973; Buchanan, 1982; Tamura et. a1., 1980). This system has many advantages: 1) It will work with very short focal length lenses. 2) The transverse field occurs in an area where it can be carefully controlled and is not subject to inhomogeneities produced by irregularities in specimen topography; a consideration that becomes more important on samples which are not flat semiconductors. 3) It seems to selectively exclude at least some of the low resolution Type 2 and 3 signals produced by backscattered electrons (Buchanan, 1983). 4) It seems to be somewhat immune to the variations in collection efficiency caused by differences in specimen surface potential that are responsible for most simple charging artifacts. There are also some disadvantages: magnetic samples cannot be viewed and because there is no directional collection field at the sample, the 'shadowing' familiar from normal SEM micrographs is absent.

The method described by Volbert and Reimer (1980) involves the use of a pair of scintillator/photomultiplier detectors, one on either side of a sample with the result that there is no field on the axis. We have used this approach with a sample immersed in the lens field (Pawley \& Wall, 1982). An axial metal tube protects the beam from the effects of the collection field until just before it reaches the sample. This detector will be described further in the next section.

A final and very promising possibility is described by Russell elsewhere in this volume and grows out of our early design by Venables and Harland, (1973.). It involves the use of a microchannel plate amplifier mounted above the sample and having a hole in the middle to let the beam pass through. The front surface can be biassed slightly positively or negatively without degrading the beam as the resulting field is cylindrically symmetric. Positive bias permits detection of secondaries with high efficiency and the results described by Russell show great promise for LVSEM.

None of these schemes represents an ideal solution in that all have the potential to degrade the beam before it reaches the sample. Their efficiency, in terms of fraction of emitted secondary electrons actually collected, has not been reported, but, of course, electrons lost at this stage can only be replaced by higher beam current and a larger spot so this is an important parameter.

\section{An LVSEM Test Bench}

In 1977 we reported on a freeze-fracture chamber directly attached to an SEM with an $\mathrm{LaB}_{6}$ source and designed so that the coated fracture surface could be directly viewed using a cold stage (Pawley \& Norton, 1978). Though we had hoped that such a system would provide an image similar to that obtained from freeze-fracture TEM, we found that the resolution/contrast at 20-30 kV was insufficient to resolve even the 10-12 nm intermembrane particles normally found on fractured membrane surfaces (Pawley et a 1., 1980). We then tried to image an actual shadowed freezefracture replica suspended over a Faraday cage at room temperature (Pawley et al., 1978). Such a sample should permit very high resolution SEM imaging because, as the sample is very thin, the Type 2 and 3 signals are almost absent. However, images of the replicas showed no trace of the particles. Indeed the signal from the replica was very small altogether, about $5 \%$ of that on a solid metal surface and $i t$ was to this low signal level that we attributed our fallure. The only possible solution seemed to be to go to lower beam voltage and as there was no high resolution LVSEM equipment commercially avallable at that time, we began a modest program to develop a prototype instrument in 1980. This instrument was designed to overcome some of the problems discussed above and to produce a 1-2 nm probe at $1 \mathrm{kV}$ in order to determine whether or not images made with it were superior to those made at higher voltage (Pawley \& Wall, 1982; Pawley \& Winters, 1983). Design

A diagram of the present version of this instrument, and photos of the entire assembly and the column itself are shown in Fig. 7. The electron source is a cold FE cathode, using single crystal tungsten in the $(1,1,1)$ orfentation 


\section{James B. Pawley}

(F.E.I. Inc., Hillsboro, Oregon) and the gun is pumped from above with a $2201 / \mathrm{sec}$. ion pump. It has been designed to be rigid, compact and wellshielded from internal and external magnetic fields. The gun block has side ports for a window and to feed through both high voltage and heater currents. It is machined from a single block of stainless steel to avoid the possibility that the welds might become ferromagnetic and the cylindrical part of the first anode is made of mu-metal. The anode itself is made of a thin $M_{0}$ foll and can be heated by radiation and electron bombardment from a tungsten filament located below it to speed out-gassing. The gun isolation valve and the movable, three-position, aperture are bellowssealed into the lower part of the gun block. Below the aperture the beam enters a platinum vacuum liner tube outside of which are situated stigmator, alignment, and double-deflection scanning coils and also a small condenser lens. The beam tube is brazed to the specimen chamber which has side-ports for two scintillator/ photomultiplier secondary electron detectors, each employing a single crystal Yttrium Aluminium Garnet ( $\mathrm{Ce}^{+++}$) hemispherical scintillator (Pawley, 1974; Autrata et al, 1978, 1983), a $201 / \mathrm{s}$, watercooled ion pump and the controls for a specimen stage holding two $3 \mathrm{~mm}$ grids. A viton-sealed port on the bottom permits specimen exchange. The objective lens is of the pancake type as described by Mulvey (1982). It is excited by a 225 turn tape winding and cooled by laminar water flow past the bottom of the lower lens pole plate. The pole tip radius is $1 \mathrm{~mm}$ and the calculated lens parameters are: $f=0.54 \mathrm{~mm}, C_{c}=0.22 \mathrm{~mm}$. Mechanical alignment of the tip is performed by adjusting set screws in the spider which holds the filament assembly while looking up the axis at the tip. After tip alignment, all of the gun components are clamped rigidly together by the upper threaded ring. All other components are prealigned and clamped by bolts to the gun block except for the objective lens which can be translated $+1 \mathrm{~mm}, \mathrm{X}$ and $\mathrm{Y}$.

The electronics are a modified version of those supplied for an AMRAY 1200 microscope (AMRAY, Bedford, Mass.). Separate controls are provided for the acceleration and PMT voltage of each electron detector. The entire column is surrounded by a $400 \mathrm{~mm}$ dia. alloy cylinder which is lined with $1 \mathrm{~mm}$ thick mu-metal and to which is attached part of the isolation valve mechanism. The cylinder and the column hang from the gun ion pump which is supported by a large steel plate. This is, in turn, suspended from a steel frame using a set of pulleys and a total of 22 thicknesses of elastic cordage which provides vibration isolation (vertical resonant frequency $\cong$ $2 \mathrm{~Hz}$ ).

Operation

Initially, very sharp cathodes were used to permit operation with $V_{1}=V_{0}=1 \mathrm{kV}$. However, after a few hours of operation these tips would fail and so they were replaced by tips operating at $v_{1}=3 \mathrm{kV}$ for a tip current of $20 \mu \mathrm{A}$.

The apertures used are carefully cleaned and then coated with evaporated gold immediately before use. A $1000 \mu \mathrm{m}$ aperture is used for the coarse set-up and $100 \mu \mathrm{m}$ is used when operating the condenser lens only. A picture of a 1000 mesh Cu grid made using the $100 \mu \mathrm{m}$ aperture and the condenser lens only is shown in figure $7 \mathrm{~d}$ and shows a resolution of about $50 \mu \mathrm{m}$. This is a reasonable result considering the long working distance.

Though the lower lens produces approximately the expected magnetic field $(2.3 \mathrm{k}$ gauss, on axis $75 \mu \mathrm{m}$ above tip at $5 \mathrm{~A}$ ), we have not yet operated it successfully as part of the microscope. To begin with, the level of the signal is very low when the lens is excited and this is true even when the collection field is increased by applying $12 \mathrm{kV}$ to only one scintillator so that there is no null point on the axis. Secondly, the beam enters the fringe field well before it reaches the sample ( 7 gauss at the distance of the $F E$ cathode) and this pre-field is so strong that the optical properties of the lens seem not to be as calculated. Similar problems were encountered by Hill \& Smith (1982) when they used a similar lens in a conventional SEM.

Unfortunately, no attempt to achieve high resolution images can be made with this instrument until this problem is overcome. Therefore we plan to modify the lens by adding an upper pole piece, thereby making it more similar to the lens used in the TEM/SEM (Fig. 8). The calculated aberration constants of this lens are somewhat larger than those of the present lens but we still hope to obtain a beam of $2.5 \mathrm{~nm}$ at $1 \mathrm{kV}$.

\section{Other Limitations to High Resolution Performance}

Spatial resolution in the topographic image from the SEM is so central to one's assessment of the instrument's capabilities it has been much studied and discussed (Oatley et a 1., 1965; Pease \& Nixon, 1965; Wells, 1974a,b; Broers, 1982; Catto \& Sm1th, 1973; Wa tabe et al., 1978; Peters, 1979, 1982). As has been mentioned above, many of these analyses, when evaluating the final images, have mistaken the topographically modified Z-contrast produced by the coating material for true topographic contrast. Catto and Smith (1973) avoid this but their theoretical analysis deals strictly with the information theory aspects of the beam/specimen interaction given certain ideal conditions. Their analysis uses basic electron scattering theory to calculate the signal-to-noise ratio of the signal from small Gaussian-profile asperities on a solid gold sample versus the radius of and distance between these asperities. The analysis is performed at 10,20 , and $30 \mathrm{kV}$ and assuming a probe diameter of $0,0.5 \mathrm{~nm}$, and $5 \mathrm{~nm}$. Not surprisingly their results show the best performance at the lowest voltage where a $1.0 \mathrm{~nm}$ asperity should just be visible using a $0.5 \mathrm{~nm}$ beam.

Comforting though it is to know that such resolution is not impossible from the point of view of scattering and information theory, it should be kept in mind that there are several practical limitations to actually obtaining this performance on real samples besides probe diameter and current. Specifically these include 1) surface contamination, 2) radiation damage, 3 ) the delocalized nature of inelastic scattering and 4) beam tailing. 
Low Voltage Scanning Electron Miicroscopy
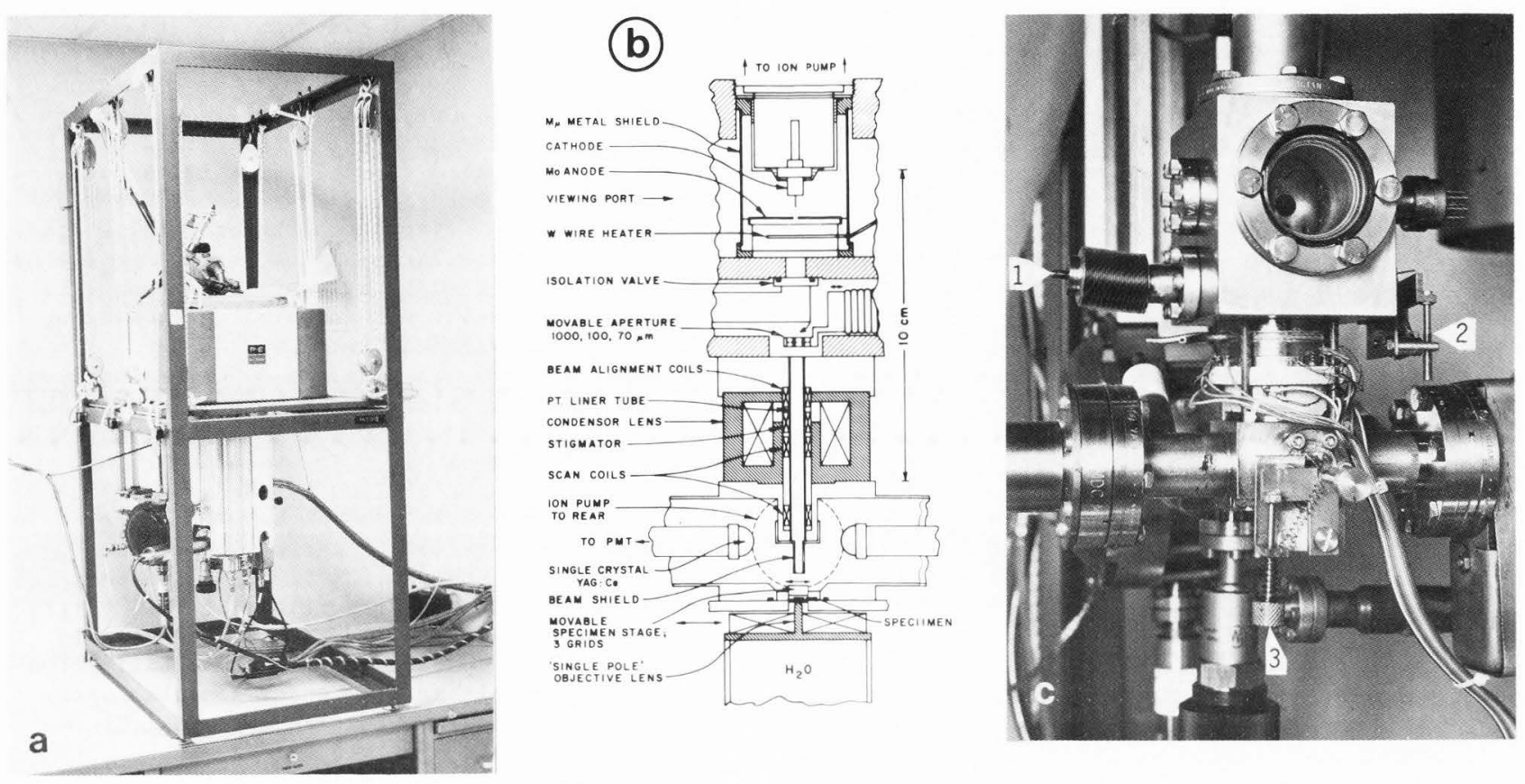

Figure 7: Low voltage SEM test bench: a) The entire column assembly showing the two ion pumps, the outer magnetic shield and the vibration isolation system. b) A diagram of the major components of the E.0. column. c) A photo of the E.0. column with the outer shield removed. (1) Bellows for isolation value. (2) Aperture motion control from side. (3) Stage motion control, similar to (2). d) An early micrograph of a 1000 mesh grid made at $1 \mathrm{kV}$ using only the condenser lens.

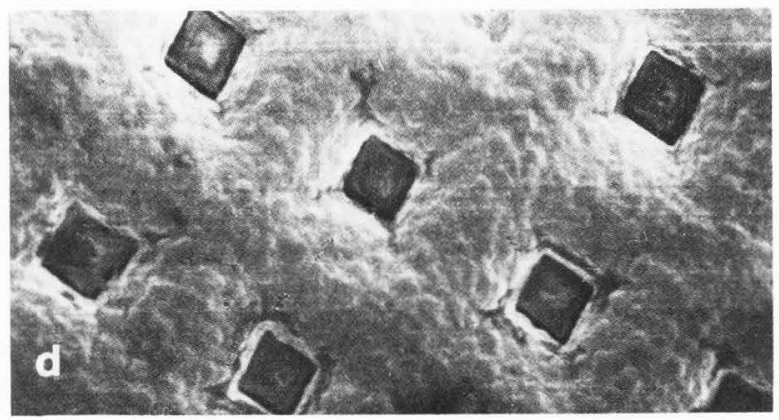

a. Present lens

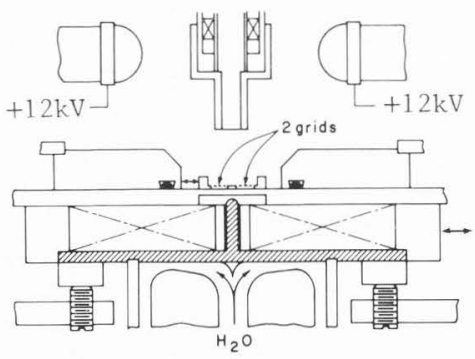

b. Proposed lens

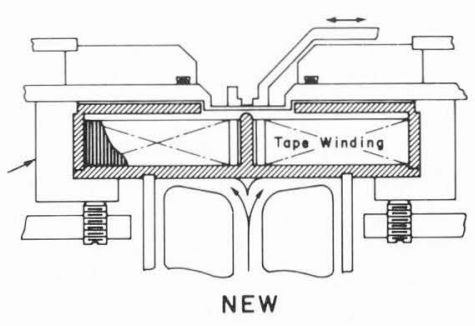

Figure 8: Present and proposed magmetic circuits

for the objective lens of the LVSEM test bench. 
Contamination

Layers of organic contamination accumulate on surfaces subjected to electron beam bombardment and the problem is more severe when small, highcurrent probes are used (Fourie, 1981). The presence of such a film is much more noticeable in the secondary electron image if a low $V_{0}$ is used. Figure $9 a$ and $b$ show two micrographs of the same a rea of Type 2 cell on a lung alveolar wall. The contaminated area can be distinguished in $9 a$, made with $V_{0}=1 \mathrm{kV}$ though it is not evident with $\mathrm{V}_{0}=10 \mathrm{kV}$ in $9 \mathrm{~b}$.

It has been assumed that any effort to produce the ultimate in topographic resolution will entail a FE source and therefore an ofl-free, generally bakeable, vacuum system where these problems would be less serious. In such an instrument the sample $i$ tself becomes the major source of contamination. Even using the cleanest possible grids and support films, a layer of contamination rapidly builds up on biological samples unless they and their surroundings are cooled sufficiently (about $-60^{\circ} \mathrm{C}$ ) to arrest the process of surface diffusion (Wall et at., 1977; Voreades \& Wal1, 1979). Therefore any effort to obtain high resolution surface images from organic materials, rather than from a metal such as gold, will probably require a cooled sample and lens assembly. Radiation Damage

The kilovolt electrons impinging on an SEM sample undergo inelastic collisions that may result in the transfer of more than a few electron volts of energy. As such, they constitute an intense source of ionizing radiation. The damage caused by this interaction to covalently bonded samples viewed in the TEM has been widely studied (Glaeser 1971, 1975, Cosslett 1978) and found to seriously limit structural information retrieval below $2 \mathrm{~nm}$. The situation is even more serious in the SEM because the entire beam energy is absorbed in the sample. Even with $\mathrm{V}_{\mathrm{O}}=1 \mathrm{kV}$ and a $10^{-11_{\mathrm{A}}}$ beam the power of the beam is $I V_{0}=10^{-8}$ watts. If we assume that one half of this energy is absorbed in the upper $10 \mathrm{~nm}$ of a sample with density 1 scanned with a raster $1000 \mathrm{~nm}$ on a side, the dose rate, $D_{r}$, is

$D_{\mathbf{r}}=\frac{10^{-8} \mathrm{j} / \mathrm{s}}{2\left(\left(10^{-4}\right)^{2} \times 10^{-6}\right) \mathrm{g}} \frac{\mathrm{g}}{10^{-5} \mathrm{j}}=5 \times 10^{10} \mathrm{Rads} / \mathrm{sec}$.

where $1 \mathrm{Rad}=10^{-5} \mathrm{j}$ deposited/gram of irradiated sample. This is a very high dose rate and, assuming a $100 \mathrm{~s}$ scan, it is more than $10^{3}$ times that common in the low-dose TEM studies designed to preserve structures below $2 \mathrm{~nm}$. It is reasonable to assume that biological samples exposed to this flux of fonizing radiation will be rapidly reduced to a highly traumatized carbon skeleton of the original structure. The image obtained will be an image of ashes and the relation 1 t bears to the original structure will be unknown. Certainly any structure of less than $2-3 \mathrm{~nm}$ should be initially treated very skeptically. On the other hand, the acceptable level of damage depends on the end-point. The 100 electrons $/ \mathrm{nm}^{2}$ thought acceptable for low dose TEM is far more than that required to inactivate all enzymes, while gross molecular shape is sometimes preserved at much higher doses (Ottensmeyer et al., 1978). As we are not seeking atomic resolution, it is not unreasonable to expect that the number and position of specific features in the original sample may be retained as lumps on the surface of the ash and, of course, the situation is less severe if the sample is really a thin metal coat covering the organic material of interest.

De-Localization of the Inelastic Scattering Event

The secondary electrons that provide the SEM signal are produced by inelastic collisions with electrons in the sample. This process is not highly localized in that it can occur when the probe electron passes some $\mathrm{nm}$ away from the electron being excited (Isaacson \& Langmore, 1974). Barth \& LePoole (1976) point out that, as the delocalization is proportional to $\mathrm{V}_{0}$, better results are to be expected at low voltage. In particular, they predict that $0.6 \mathrm{~nm}$ localization should be possible at $1 \mathrm{kV}$ under somewhat optimistic experimental circumstances. $\left(C_{c}, C_{s}=\right.$ $\left.0.07 \mathrm{~mm}, \Delta \mathrm{V}<0.2 \mathrm{~V}, \alpha=4 \times 10^{-2} \mathrm{rad}_{.}\right)$

Another consideration seldom discussed in terms of topographic imaging involves the effects of low-energy X-rays. The spectrum of Bremsstrahlung $X$-ray production increases exponentially at low energy $(1000-10 \mathrm{eV})$ but these interactions are usually ignored because the Xrays so produced are absorbed so strongly by the sample that very few of them leave it. Their generation is of interest here because their absorption in the sample can result in the production of a secondary electron a few $\mathrm{nm}$ away from their generation site. We are unaware of quantitative data at these voltages and on this size scale that would permit an accurate estimate of the size of this effect but it could be an important factor.

As these effects act independently from all the electron optical blurring functions, they should reduce the actual point-to-point resolution by at least an additional $0.5 \mathrm{~nm}$ from that theoretically calculated from electron optical and electron scattering considerations. Beam Tailing

When speaking of the beam diameter of a focused spot, it is customary to assume that the current density resembles a Gaussian distribution or an Airey disk and to refer to $i$ ts diameter at half maximum or the distance over which the intensity drops from $80 \%$ to $10 \%$ of the peak value. As has been pointed out by Cliff \& Kenway (1982), beams in probe forming instruments are often nongaussian for various reasons, and in particular, they of ten have a small central peak surrounded by a much wider "shadow" of lower but significant intensity. This shadow greatly complicates the criteria for visibility as measured by Catto and Smith (1973). When discussing small probes it is essential to keep in mind the fraction of the total current actually in the central spot. 


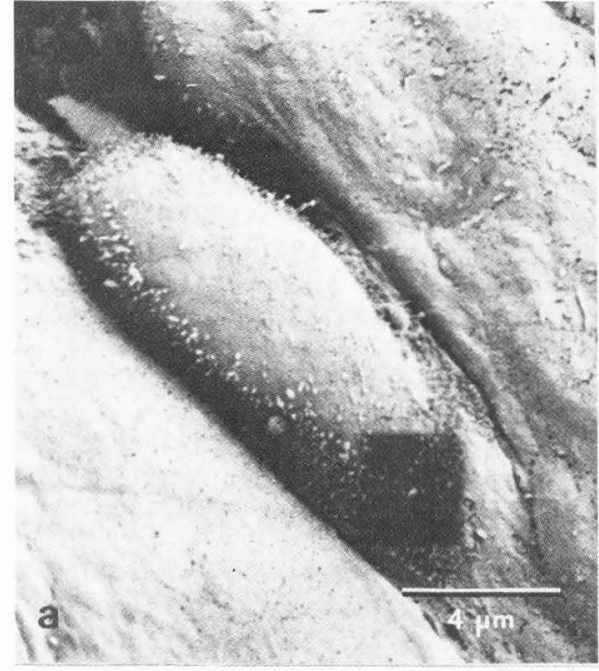

$1 \mathrm{kV}$

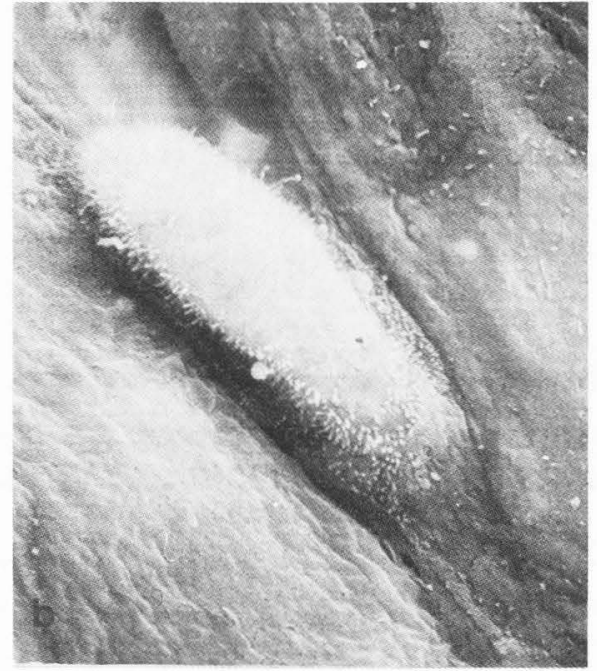

$10 \mathrm{kV}$

\section{The Prospects for Topographic Imaging in the LVSEM}

In light of all these problems, what performance is it reasonable to expect under the best possible conditions and what are these conditions? As discussed above, the ideal microscope should probably employ a low-current cold-field-emission source and a lens with short focal length which also permits collection of the secondary electron signal. Beyond that, there are many theoretical advantages of operating it at liquid helium temperature. Not only is surface contamination negligible but superconducting materials are also perfect shields against stray electromagnetic fields (Dietrich et al., 1977). Furthermore, the low frequency nolse and energy spread of the gun would be somewhat less. Though the primary ionizing event that produces radiation damage would not be eliminated, and chemical reactions would still occur following the accumulation of sufficient beam-produced free radicals, it is still probable that many low molecular weight species produced by the interaction might remain frozen nearly in place at these temperatures. This would not preserve molecular integrity but to some extent, the lumps would not move.

One disadvantage, aside from considerable complexity, might be increased charging artifacts. Even semiconductors become insulators at these temperatures and it might be necessary to lightly coat all samples. Furthermore, trace amounts of residual gas could create unwanted insulators if they became frozen onto sensitive surfaces.

With such an instrument it would seem that uncoated cubic surface features of low Z material as small as $3 \mathrm{~nm}$ on a side might be detectable on a flat solid surface as long as they were not destroyed by radiation damage. Two such objects could be distinctly imaged if separated by about $5 \mathrm{~nm}$ center to center. Information from lightly coated $(1-1.5 \mathrm{~nm})$ samples might be somewhat better, assuming the coating material was chosen for low secondary electron mean-free-path (Everhart, 1970) and that we are now referring to the size of the surface features after coating. Though this is the same size range that is covered by the best replica techniques, it is important to remember the benefits of directly imaging the actual sample. Oatley (1982) points out that in the early $1960^{\prime}$ s commercial introduction of the SEM was delayed by the logic that, as replica techniques had higher resolution, there would be no market for the SEM. This analysis failed to take into account the extent to which specimen preparation is simplified and the areas of possible application increased by avolding the necessity of having to produce a replica. Because of a willingness to accept the SEM's lower resolution in order to be able to examine the surface of a larger and more convoluted sample, the instrument came into common use and $i t$ has now been improved to the point where it may no longer even have to defer to the replica techniques in terms of resolution. When this happens it will be a considerable achievement.

Apart from ultimate performance at the limit of topographic imaging, important improvements in the low voltage performance of most current instruments should lead to their increased use in the $2-5 \mathrm{kV}$ range by a wide variety of users (Fig. 1b). The next practical step might be the use of a TEM lens with properties similar to those diagrammed in Fig. 6 in conjunction with an FE source to produce the first really high resolution LVSEM results. The important test should be whether or not going to a higher voltage produces more information about the topography of a sample or merely sharper pictures of the metal grains of the coating material.

\section{Acknowledgements}

Thanks are due to the AMRAY Corporation (Bedford, Mass.) and to the Wisconsin Alumni Research Foundation for supplying the electronics and vacuum pumps (respectively) used in building the LVSEM test bench and to the National Institutes of Health for support through Grant RR-00570-14 to the Madison HVEM Biotechnology Resource. Personal thanks are also due to $\mathrm{Dr}$. J. Wall (Brookhaven National Laboratory) for his 
generous assistance and encouragement in the design of the test bench and to Mr. M. Winters, without whom it would not have been completed. Dr. Autrata (Institute of Scientific Instruments, Brno) kindly provided the single crystal YAG scintillators and Dr. E. de Harven (University of Toronto) and Dr. J. Bastacky (Berkeley, CA) allowed me to use their samples for Figures 3 and 9 respectively. Figures 3 and 9 were taken by Mr. Naito (Hitachi, Mt. View, CA) on an S-800 FE SEM while Figure 1 was made by Mr. R. Kreiger (International Scientific Instruments, Mt. View, CA) on an SS-40 conventional SEM. Finally, thanks a re due to Mr. W. McInvaille and Ms. G. Krewson for their patience with the manuscript and to Dr. D. Joy who read the manuscript and allowed me to use Fig. 4a from a preprint of his recent paper.

\section{References}

Adachi K, Hojou L, Katoh M, Kanaya K. (1983) High resolution shadowing for electron microscopy by sputter deposition. U1tramicros. 12, $17-29$.

Anger K, Lischke B, Sturm M. (1983) Material surfaces for electron-optical equipment. Scanning $5,39-44$.

Arro E, Collins VP, Brunk UT. (1981) High resolution SEM of cultured cells: preparatory procedures. Scanning Electron Microsc. 1981; II: $159-168$.

Autrata R, Schauert P, Kvapil JS, Kvapil J. (1978) A single crystal of YAG--new fast scintillator in SEM. J. Phys. E: Sci. Instrum., II, $707-708$.

Autrata R, Schauer P, Kvapil J, Kvapil JR. (1983). Single-crystal aluminates - A new generation of scintillators for scanning electron microscopes and transparent screens in electron optical devices. Scanning Electron Micros. 1983; II: 489-500.

Bal1 MD, McCartney DG. (1981) The measurement of a tomic number and composition in a SEM using backscattered detectors. J. Micros. 124(1), 57-68.

Ballard DB. (1972) Comparison and evaluation of specimens for resolution standards. Scanning Electron Micros. 1972: 121-128.

Banbury JR, Nixon WC. (1970) Voltage measurement in the scanning electron microscope. Scanning Electron Micros. 1970: 473-480.

Barth JE, Poole JB. (1976) Low voltage electron microscopy - how low? Ultramicros. 1, 387-388.

Bauer B, Speidel R. (1981) Influence of energy spread of field-emitted electrons on resolution in the scanning transmission electron microscope (STEM). Ultramicros. 6, 281-286.
Boersch H. (1954) Experimentele Bestimmung der Energieverteilung in thermisch ausgeloesten Elektronen Strahlen. Z. Phys. 139, 139.

Boyde A. (1971) A review of problems of interpretation of the SEM image with special regard to methods of specimen preparation. Scanning Electron Micros. 1971: 1-8.

Boyes ED. (1984) High Resolution at Low Voltage: The SEM Philosopher's Stone? EMSA (San Francisco Press, SF) 42, 446-4 $\overline{50 .}$

Brandis EK, De Stafeno J, Flitch R, Landenberger R. (1984) Low voltage SEM, Auger, and XPS of Surface Contaminants EMSA (San Francisco Press, S.F.) 42, 458-459.

Bresse JF. (1982) Quantitative investigations in semiconductor devices by electron beam induced current mode: A review. Scanning Electron Micros. 1982; IV: 1487-1500.

Broers AN, Panessa BJ, Gennaro, JF. (1975) High-resolution scanning electron microscopy of bacteriophage $3 \mathrm{C}$ and $\mathrm{T} 4$. Science 189 , $637-639$.

Broers AN. (1974) Recent advances in scanning electron microscopy with lanthanum hexaboride cathodes. Scanning Electron Micros. 1974: $9-18$

Broers AN. (1982) Resolution in surface scanning electron microscopy of bulk materials. Ultramicros. 8, 137-144.

Buchanan R. (1982) New SEM lens give sharpest micrographs yet. Industrial Research and Development/Aug, 92-95.

Buchanan R. (1983) The scanning electron microscope for semiconductor application. Microelectronic Manufacturing and Testing/Feb., 22-24.

Buchanan R, Menzel E. (1984) Some recent develop-

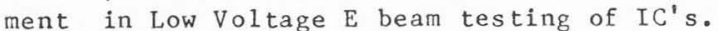
EMSA (San Francisco Press, S.F.) 42, 460-464.

Catto CJD, Smith KCA (1973) Resolution limits in the surface scanning electron microscope. $\mathrm{J}$. of Micros. 98, 417-435.

Clarke DR. (1970) Review: Image contrast in the scanning electron microscope. J. of Material Sci. 5, 689-708.

Cliff G, Kenway PB. (1982) The effect of spherical aberration in probe-forming lenses on probe size, image resolution, and X-ray resolution in scanning transmission electron microscope. Microbeam Analysis, 107-110.

Cosslett VE. (1978) Radiation damage in the high resolution electron microscopy of biological materials: a review. J. Micros. 113(2), $113-129$. 
Crewe AV. (1973) Production of electron probes using a field emission source. In: Progress in Optics XI (Ed. by E. Wolf), pp. 225-246. (Elsevier Publishers) North-Holland.

Crewe AV, Eggenberger DN, Wall J, Welter LM. (1968) Electron gun using field emission sources. Rev. Sci. Inst. 39, 576-583.

Crewe AV, Isaacson M, Johnson D. (1971) A high resolution electron spectrometer for use in transmission scanning electron microscopy. Rev. Sci. Inst. 42(4), 411-420.

Crewe AV, Lin PSD. (1976) The use of backscattered electrons for image purposes in a scanning electron microscope. Ultramicros. 1, 231-238.

Crewe AV, Wall J, Langmore J. (1970) Visibility of a single atom. Science 168, 1338-1340.

Dietrich I, Rox F, Knapek E, Lefrank G, Nachtrieb $K$, Weyl R, Zerbst H. (1977) Improvements in electron microscopy by application of superconductivity. Ultramicros 2, 241-249.

Dilly PN. (1980) Enhanced contrast of cilia using low accelerating voltage as an aid to low power survey and counting. Scanning 3 , 283-284.

Evans AC, Franks J. (1981) Specimen coating for high resolution scanning electron microscopy. Scanning 4 , 169-174.

Everhart TE. (1970) Contrast and resolution in the scanning electron microscope. Third Annual Cambridge Stereoscan Colloquium, (available from Cambridge Instr. Co., Monsey, NY), 1-8.

Everhart TE, Thornley, RFM. (1960) Wide-band detector for micro-microampere low-energy electron current. J. Sci. Intrum. 37, 246-248.

Everhart TE, Wells OC, Oatley CW. (1959) Factors affecting contrast and resolution in the scanning electron microscope. J. Electron. Control 7 , 97-111

Fourie JT. (1981) Electric effects in contamination and electron beam etching. Scanning Electron Micros. 1981; I: 127-134.

George, EP, Robinson, VNE. (1975) Topographic intensity profiles in the scanning electron microscope--cubes. J. Micros. 105(3), 289-297.

Glaeser, RM. (1971) LImitations to significant information in biological electron microscopy as a result of radiation damage. J. Ultrastruct. Res. 36,466 .

Glaeser, RM. (1975) Radiation damage and biological electron microscopy. In: Physical Aspects of Electron Microscopy and Microbeam Analysis (Ed: B. M. Siegel and D. R. Beaman), Wiley, New York, pp. 205-230.
Haggis, GH. (1982) Contribution of scanning electron microscopy to viewing internal cell structure. Scanning Electron Micros. 1982; II: 751-763.

Haggis, GH, Bond, EF. (1979) Three-dimensional view of the chromatin in freeze-fractured chicken erythrocyte nuclei. Journal of Microscopy $115(3), 225-234$.

Haggis, GH, Schweitzer, I, Hall, R, Bladon T. (1983) Freeze fracture through the cytoskeleton, nucleus and nuclear matrix of lymphocytes studied by scanning electron microscopy. J. of Micro. 132(2), 185-194.

Hainfield, JF. (1977) Understanding and using field emission sources. Scanning Electron Micros. 1977; I: 591-604.

Hasselbach F, Rieke U. (1982) Spatial distribution of secondaries released by backscattered electrons in silicon and gold for 20-70 keV primary energy. Proc. Europ. Reg. Conf. Electron Microscopy I, (Deutsche Gesellschaft fur Elektronenmikroskopie e.v.), 253-254.

Hasselbach, F, Rieke, U, Straub, M. (1983) An imaging secondary electron detector for the scanning electron microscope. Scanning Electron Micros. 1983; II: 467-478.

Hill, R Smith, KCA. (1982) The single-pole lens as a scanning electron microscope objective. Scanning Electron Micros. 1982; II: 465-471.

Ichinokawa T, Sekine M, Gur ZS, Ishikawa, A. (1982) Electron optical properties of low energy field emission gun in the energy range from 100 to $2000 \mathrm{eV}$. Proc. Europ. Reg. Conf. Electron Microscopy I, (Deutsche Gesellschaft fur Elektronenmikroskopie e.v.), 351-352.

Isaacson M, Langmore, JP. (1974) Determination of non-localization of the inelastic scattering of electrons by electron microscopy. Optik 41(1), 92-96.

Joy DC, Maher DM. (1976) Low-loss images in a STEM/TEM microscope. EMSA 34, (Claitor's Publ. Div., Baton Rouge, LA), 496-497.

Joy DC, Newbury DE, Myklebust RL. (1982) The role of fast secondary electrons in degrading spatial resolution in the analytical electron microscope. J. Micros. 128 .

Joy DC. (1984a) Beam interactions, contrast and resolution in the SEM. Microelectronic Engineering (in press).

Joy, DC. (1984b) Resolution in Low Voltage SEM, EMSA 42, (San Francisco Press, SF), 444-445.

Keery WJ, Leedy KO, Galloway KF. (1976) Electron beam effects on microelectronic devices. Scanning Electron Micros. 1976; I: 507-514. 
James B. Pawley

Kemmenoe BH, Bullock GR. (1983) Structure analysis of sputter-coated and ion-beam sputter-coated films: a comparative study. J. of Micro. $132(2), 153-163$.

Koike H, Namae T, Watabe T, Milkajiri A. (1973) An approach to microanalys is with the electron microscope. JEOL News 10 e(4), 2-8.

Koike H, Ueno K, Suzuki M, Matsuo T, Aita S, Shibatomi K. (1971) High resolution scanning device for the JEM-100B electron microscope. JEOL News 9 e(3), 20-21.

Kokubo Y, Ueno K, Iwatsuki M, Koike H. (1975) An application of strongly excited objective 25 lens to low loss image. EMSA (Claitor's Publishing Div., Baton Rouge, LA), 33, $138-139$.

Kosuge T, Hashimoto H, Sato M, Komoto S. (1970) Quality of the secondary electron image at low accelerating voltage. In: Microscopie electronique, vol. I (Ed. by P. Favard), pp. 201-202. Societe Francaise de Microscopie Electronique, Paris.

Kotera M, Murata K, Nagami K. (1981) Monte Carlo simulation of a $1-10-\mathrm{keV}$ electron scattering in a gold target. J. Appl. Phys. 52(2), 997-1003.

Kuo HPK, Siegel BM. (1976) A field emission probe forming system with a magnetic pre-accelerator lens EMSA 34 (Claitor's Publ. Div., Baton Rouge, LA), 522-523.

Kursheed A, Dinnis AR. (1983) Computation of trajectories in voltage contrast detectors. Scanning 5, 25-31.

Langmuir DB. (1937) Theoretical limitations of cathode-ray tubes. Proc. I.R.E. 25(8), 977-991.

Le Gressus C, Duraud JP, Massignon D, Deacon OL. (1983) Electron channelling effect on secondary electron image contrast. Scanning Electron Micros. 1983; II: 537-542.

Lin PSD, Lamvik MK. (1975) High resolution SEM at the subcellular level. J. Micros. 103, 249-257.

Miyoshi M, Ishikawa M, Okumura K. (1982) Effects of electron beam testing on the short channel metal oxide semiconductor characteristics. Scanning Electron Micros. 1982; IV: 15071514 .

Mulvey T. (1982) Unconventional lens design. In: Magnetic Electron lens properties (Ed. P. Hawkes). Springer-Verlag, Berlin, $359-412$.

Murata K, Kyser DF, Ting CH. (1981) Monte Carlo simulation of fast secondary electron production in electron beam resists. J. Appl. Phys. 52, 4396-4405.
Nakagawa S, Shibuki Y, Sahara K, Norioka S. (1982) High performance analytical scanning electron microscope provided with $\mathrm{C}-\mathrm{F}$ mini lens and zoom condenser lens system. Proc. Europ. Reg. Conf. Electron Microscopy I, (Deutsche Gesellschaft fur Elektronenmikroskopie e.v.), 389-390.

Newman TH, Pease RFW, Polasko KJ, Yao YW. (1984). Lithography with low energy electrons. EMSA (San Francsico Press, SF) 42, 468-469.

Niedrig H. (1978) Physical background of electron backscattering. Scanning 1(1), 17-34.

Nomura S, Komoda T, Kameryo T, Nakaizumi V. (1973) Stable field emission gun with an electronic feedback system. Scanning Electron Micros. 1973: 65-72.

Datley CW (1969) Isolation of potential contrast in the scanning electron microscope. J. Phys. E. 2(2), 742-744.

Oatley CW. (1972) The Scanning Electron Microscope, part I, The Instrument. The University Press, Cambridge, 1-194.

Oatley CW. (1975) The tungsten filament gun in the scanning electron microscope. J. Phys. E.: Scientific instruments $\underline{8}, 1-5$.

Oatley CW. (1982) The early history of the scanning electron microscope. J. Appl. Phys. $53(2)$, R1-R13.

Datley, CW (1983) Electron currents in the specimen chamber of a scanning microscope. J. Phys. E. 16(4), 308-312.

Oatley, CW, Everhart TE. (1957) The examination of $\mathrm{p}-\mathrm{n}$ junctions with the scanning electron microscope. J. Electronics II(6), 568-570.

Oatley CW, Nixon WC, Pease RFW. (1965) Scanning electron microscopy. In: Advan. in Electronics \& Electron Physics, pp. 181-247. Academic Press, New York.

Ohshita A, Shimoyana H, Maruse S. (1978) Brightness in the hot cathode electron at high emission densities. J. Electron. Micros. $27(4), 253-257$.

Ottensmeyer FP, Bazett-Jones DP, Rust HP, Weiss K, Zemlin F, Engel A. (1978) Radiation exposure and recognition of electron microscopic images of protamine at high resolution. U1 tramicros. 3 , 191-202.

Pawley JB. (1972) Charging artifacts in the scanning electron microscope. Scanning Electron Micros. 1972: 153-160.

Pawley JB (1974). Performance of SEM scintillator materials. Scanning Electron Micros. 1974: $27-34$ 
Pawley JB. (1984a) Low Voltage SEM, J. Microscopy $13,387-410$.

Pawley JB (1984b) SEM at Low Beam Voltage, EMSA (San Francisco Press, SF) 42, 440-443.

Pawley JB (1984C) Strategy for locating and eliminating sources of main frequency magnetic stray field, Scanning (in press).

Pawley JB, Hook G, Hayes TL, Lai C. (1980) Direct scanning electron microscopy of frozenhydrated yeast. Scanning 3(3), 219-226.

Pawley JB, Hayes TL, Hook G. (1978) Preliminary studies of coated complementary freezefractured yeast membranes viewed directly in the SEM. Scanning Electron Micros. 1978; II: $683-690$.

Pawley JB, Norton JT (1978) A chamber attached to the SEM for fracturing and coating biological samples. J. Micros. 112(1), 169-182.

Pawley JB, Wall J. (1982) A low voltage SEM optimized for high resolution topographical imaging. Proc. Europ. Reg. Conf. Electron Microscopy 1 (Deutsche Gesellschaft fur Elektronenmikroskope e.V.), 383-384.

Pawley JB, Winters MP. (1983) Low voltage SEM. 4lst Ann. Proc. EMSA (San Francisco Press, SF) 41, 448-492.

Pease RFW, Nixon WC. (1965) High Resolution SEM. J. Sci. Instrum. 42, 31-35.

Peters K-R. (1979) Scanning electron microscopy at macromolecular resolution in low energy mode on biological specimens coated with ultra thin metal films. Scanning Electron Micros. 1979; II: 133-148.

Peters K-R. (1982) Conditions required for high quality high magnification images in secondary electron-I scanning electron microscopy. Scanning Electron Micros. 1982; IV: 1359-1372.

Peters K-R, Green SA (1983) Macromolecular structures of biological specimens are not obscured by controlled osmium impregnation. EMSA 1983 (San Franscisco Press, SF), 606-607.

Peters K-R, Palade GE, Schneider BG, Papermaster DS. (1983) Fine structure of periciliary ridge complex of frog retinal rod cells revealed by ultrahigh resolution scanning electron microscopy. J. Cell Biol. 96, 265-276.

Pfeiffer HC. (1972) Basic limitations of probe forming systems due to electron-electron interactions. Scanning Electron Micros. 1972: $113-120$

Pfeiffer HC. (1982) Probe forming systems. Proc. Europ. Reg. Conf. Electron Microscopy I (Deutsche Gesellschaft fur Elektronenmikroskope e.V.), 435-442.
Polasko KJ, Yau YW, Pease RFW. (1983) Low energy electron beam lithography. Optical Engineering 22(2), 195-198.

Pomposo TF, Coates VJ. (1983) Computerized electron-beam line-width measuring and inspection: a new tool. Silicon Processing, ASTM STP 804; DC Gupta (ed.), American Soc. for Testing \& Materials, 501-508.

Reimer L. (1978) Scanning electron microscopypresent state and trends. Scannning 1(1), 3-16.

Reimer L. (1979) Electron - specimen interactions. Scanning Electron Micros. 1979; II: 111-124.

Reimer L, Volbert B. (1979) Detector system for backscattered electrons by conversion to secondary electrons. Scanning $2,238-248$.

Saito S, Nakaizumi Y, Mori H, Nagatani T. (1982) A field emission SEM controlled by microprocessor. EM I, (Deutsch Gesellschaft fur Elektronenmikroskopie e.v.), 379-380.

Sawada H. (1981) Three dimensional observation on muscular tissues. Scanning Electron Micros. 1981; IV: 7-15.

Seiler H. (1976) Determination of the "information depth" in the SEM. Scanning Electron Micros. 1976; I: 9-16.

Shaffner TJ, Hearle JWS. (1976) Recent advances in understanding specimen charging. Scanning Electron Micros. 1976; I: 61-70.

Tamura N, Saito H, Ohyama J, Aihara R, Kabaya A. (1980) Field emission SEM using strongly excited objective lens. EMSA 38, (Claitor's Pub. Div., Baton Rouge, LA), 68-69.

Tanaka K. (1980) Scanning electron microscopy of intracellular structures. In: International Review of Cytology, Vol. 68, pp. 97-115. Academic Press, New York.

Tanaka K. (1981) Demonstration of intracellular structure by high resolution scanning electron microscopy. Scanning Electron Micros. 1981; II: $1-8$.

Thornley RFM. (1960) Recent developments in scanning electron microscopy. In: Proc. Eur. Reg. Conf. Elect. Micros. (Deutsche Gesellschaft fur Elektronenmikroskopie e.v.) (Ed. by A. L. Houwink and B. J. Spit), pp. 173-176.

Todokoro H, Fukuhara S, Sakitani Y. (1980) Low acceleration SEM. EMSA 38, (Claitor's Publ. Div., Baton Rouge, LA), $\overline{70}-71$.

Todokoro H, Fukuhara S, Komoda T. (1983) Stroboscopic scanning electron microscope with $1 \mathrm{keV}$ electrons. Scanning Electron Micros. 1983; II: 561-568. 
Todokoro H, Yoneda S, Yamaguchi K. (1984) Stroboscopic testing of LSI's with LVSEM, EMSA 42 (San Francisco Press, SF), 464-468.

Tuggle DW, Watson SG. (1984) A low voltage field enission column with a Schottky emitter, EMSA, 42 (San Francisco Press, SF), 454-457.

Van Der Mast KD. (1983) Field emission, development and possibilities. J. of Micros. 130(3), 309-324.

Varnell GL. (1981) Micron and submicron lithography for VLSI device fabrication. Scanning Electron Micros. 1981; I: 343-350.

Venables JA, Harland CJ. (1973) Electron backscattering patterns - A new technique for obtaining crystallographic information in the SEM, Phil. Mag., 27, 1193-1200.

Volbert B. (1982a) Signal mixing techniques in scanning electron microscopy. Scanning Electron Micros. 1982; III: 897-905.

Volbert B. (1982b) True surface topography: the need for a signal mixing. Proc. Europ. Reg. Conf. Electron Microscopy I (Deutsche Gesellschaft fur Elektronenmikroskopie e.v.), 233-239.

Volbert B, Reimer L. (1980) Advantages of two opposite Everhart-Thornley detectors in SEM. Scanning Electron Micros. 1980; IV: 1-10.

Voreades D, Wall JS. (1979) Contamination and reverse contamination at low temperature. EMSA 37 (Claitor's Pub. Div., Baton Rouge, LA), $\overline{358}-359$.

Wall J, Bittner J, Hainfeld J. (1977) Contamination at low temperature. EMSA 35 (Claitor's Pub. Div., Baton Rouge, LA), 558-559.

Watabe T, Hoshino T, Harada Y. (1978) The visibility of individual ferritin particles in a scanning electron microscope with a field emission gun. U1tramicroscopy $\underline{3}$, 19-27.

Wells OC. (1974a) Resolution of the topographic image in the SEM. Scanning Electron Micros. 1974: 1-8.

Wells OC. (1974b) Scanning Electron Microscopy. McGraw Hill, New York.

Wells OC (1978) Penetration effect at sharp edges in the scanning electron microscope.

Scanning 2 , 199-216.

Wells, OC (1979) Effects of collector take-off angles and energy filtering on the BSE image in the SEM. Scanning $2,199-216$.

Wells OC, Broers AN, Bremer CG. (1973) Method for examining solid specimens with improved resolution in the scanning electron microscope (SEM). Appl. Phys. Lett. 23(6), 353-
355.

Welter LM, Coates VJ. (1974) High resolution scanning electron microscopy at low accelerating voltages. Scanning Electron Micros. 1974: 59-66.

Welter LM, McKee AN. (1972) Observations on uncoated, nonconducting or thermally sensitive specimens using a fast scanning field emission source SEM. Scanning Electron Micros. 1972: 161-168.

Wiesner JC. (1973) Characteristics and applications of pointed cathodes in SEM's. Scanning Electron Micros. 1973: 33-40.

Wiesner JC, Everhart TE. (1973) Point-cathode electron sources - electron optics of the initial diode region. J. Appl. Phys. $44(5), 2140-2148$. and $45(6), 2797-2798$.

Wilska AP. (1964) Low-voltage electron microscopy: A 6-kV instrument. J. Royal Micros. Soc. $83(1 \& 2), 207-211$.

Wilska AP. (1965) Expectations and limitations of low voltage electromiscroscopy. Laboratory Investigation 14(6), 825-828.

Yamazaki S, Kawawoto H, Saburi K, Naktasuka H, Buchanan R. (1984) Improvement in SEM gun brightness at low $\mathrm{kV}$ using an intermediate extraction electrode. Scanning Electron Micros. 1984; I: 23-28.

Yau YW, Pease RFW, Iranmanesh AA, Polasko KJ. (1981) Generation and applications of finely focused beams of low-energy electrons. J. Vac. Sci. Technol. 19(4), 1048-1052. 